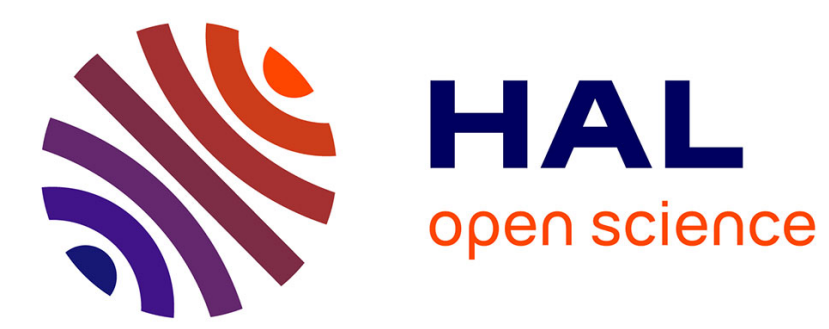

\title{
Amenities and risk in forest management
}

Marielle Brunette, Stéphane Couture, Eric Langlais

\section{To cite this version:}

Marielle Brunette, Stéphane Couture, Eric Langlais. Amenities and risk in forest management. 2020. hal-01189499

\section{HAL Id: hal-01189499 \\ https://hal.science/hal-01189499}

Preprint submitted on 6 Jun 2020

HAL is a multi-disciplinary open access archive for the deposit and dissemination of scientific research documents, whether they are published or not. The documents may come from teaching and research institutions in France or abroad, or from public or private research centers.
L'archive ouverte pluridisciplinaire HAL, est destinée au dépôt et à la diffusion de documents scientifiques de niveau recherche, publiés ou non, émanant des établissements d'enseignement et de recherche français ou étrangers, des laboratoires publics ou privés. 

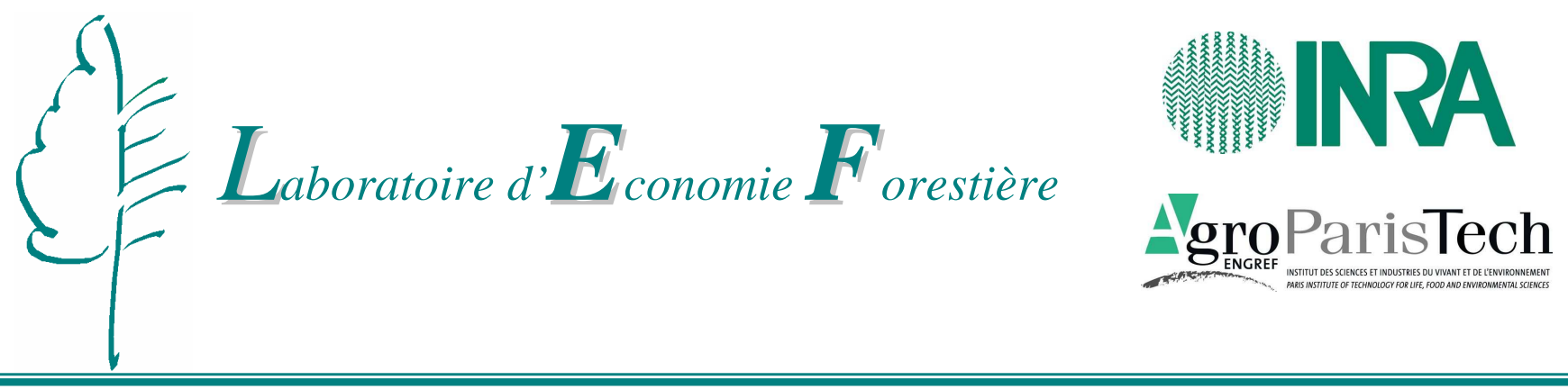

\title{
Amenities and Risk in Forest Management
}

\author{
Marielle BRUNETTE \\ Stéphane COUTURE \\ Eric LANGLAIS
}

Février 2009

Document de travail

$\mathbf{n}^{\circ}$ 2009-01 


\title{
Amenities and Risk in Forest Management
}

\author{
Marielle BRUNETTE ${ }^{1,2,3}$ \\ Stéphane COUTURE, 3 \\ Eric LANGLAIS ${ }^{2,3,4}$
}

Février 2009

\author{
Document de travail du LEF $\mathrm{n}^{\circ} \mathbf{2 0 0 9 - 0 1}$
}

\begin{abstract}
Résumé
Aménités et risque en gestion forestière

L'objectif de l'article est d'analyser les décisions de couverture d'un propriétaire forestier privé non-industriel en présence d'incertitude sur la production de bois. Les décisions de récolte sont étudiées ainsi que deux stratégies de couverture : une pratique financière et une pratique physique. Nous développons un modèle de décisions de couverture et de récolte à deux périodes lorsque le propriétaire valorise les services d'aménités fournis par la forêt. Nous étudions les propriétés des décisions de récolte et de couverture présentes et futures. Nous montrons que, excepté lorsque les deux instruments sont des substituts parfaits, le propriétaire choisit un seul outil, son choix dépendant du taux de rendement de la stratégie de couverture. Nous prouvons aussi que plus l'utilité marginale retirée des aménités est élevée, plus le propriétaire réduit sa récolte. Nous fournissons une analyse de statique comparative sur la récolte présente et future et sur la stratégie de couverture. Nous nous intéressons à l'impact d'un accroissement des stocks initiaux (richesse et bois), des prix du bois (périodes 1 et 2), du coût d'opportunité des instruments de couverture (taux de rendement pour la pratique financière et coût du processus de régénération pour la pratique physique) et de l'espérance de risque. Nous montrons, par exemple, qu'une hausse de l'espérance de risque a un impact négatif sur la récolte de période 1 et sur le recours aux deux instruments de couverture, alors que l'impact sur la récolte de période 2 est positif pour la pratique financière et nul pour la pratique physique.
\end{abstract}

Mots clés : aménités, risque, gestion forestière, stratégie de couverture, récolte.

\begin{abstract}
The objective of the paper is to analyze the risk management behavior of a non-industrial private forest owner under uncertainty about timber production. Two types of hedging strategies with harvesting decisions are studied: a financial practice versus a physical one. We develop a two-period model of hedging and harvesting decisions when the forest owner values the amenity services of forest. We study the properties of optimal current and future harvesting and hedging decisions. We show that, except when both hedging instruments are perfect substitutes, the forest owner chooses a single tool, her/his choice depending on the rate of return of the hedging instrument. We also prove that the greater the marginal utility of amenity services, the smaller the harvesting amount. We provide a comparative statics analysis on current and future harvesting and on the hedging strategies. We are interested in the impact of an increase in initial stocks (wealth and timber), timber prices (periods 1 and 2), opportunity costs of the hedging instruments (rate of return for savings and cost of the regeneration process for physical practice) and expected risk. We show, for example, that an increase in expected risk has a negative impact on period 1 harvesting and the use of hedging tools for both strategies, while the impact on period 2 harvesting is positive for savings and null for physical practice.
\end{abstract}

Key words: amenities, risk, forest management, hedging strategies, harvesting.

Classification JEL : D81, Q23, Q26, Q54.

\footnotetext{
${ }^{1}$ BETA-REGLES (Université Nancy 2) Email marielle.brunette@ nancy-engref.inra.fr

2 INRA, UMR 356 Economie Forestière, F-54000 Nancy, France

${ }^{3}$ AgroParisTech, Engref, Laboratoire d'Economie Forestière, F-54000 Nancy, France

${ }^{4}$ Université Nancy 2, UFR Administration Economique et Sociale
} 


\section{Introduction}

In many countries of Europe, forests are managed by small Non-Industrial Private Forest (NIPF) owners with some specific characteristics that have an impact on forest management. Two main characteristics of NIPF owners can be highlighted. The first one is that the main objective of NIPF owners is to smooth consumption over time. They therefore face a saving-consumption problem linked with forest management. The second one is that NIPF owners have positive utility due to amenity functions of forests along with the revenue from timber sales. Recently it has been proved that NIPF owners confer some private value on the amenity services of forest stock, even if there are no financial incentives to these functions ([1] ; [2]). Forests provide a large variety of nontimber services, such as walking, landscape and mushroom crops, produced jointly with timber and vanishing with the standing stock. The saving-consumption problem and joint production property affect the way NIPF owners manage their forest.

Furthermore NIPF owners face natural risk that affects these two main characteristics (consumption smoothing and amenity services). For several years, the frequency and severity of extreme climatic events have seemed to increase and they have caused more and more damage in forestry management [3]. Natural disasters affect the timber production of forests, but also the amenity services to be got from standing stock. Amenities therefore reinforce the interest of protection and hedging measures against such risk. In spite of the presence of market insurance, ${ }^{1}$ NIPF owners generally give preference to access to perfect financial markets and different forest management practices to smooth consumption across different states of nature due to risk. Recent exceptional natural events in Europe have focused attention on programs to give NIPF owners incentives to reduce the risk of damage from natural events. ${ }^{2}$ Therefore, before analyzing different policy instruments, it is very important to understand the hedging behavior of NIPF owners.

Regarding the technology of risk exchange and the design of hedging practices, our paper mainly focuses on the use of financial markets (savings decisions) and forest management practices (close to self-insurance decisions). Note that from a conceptual point of view, each of these instruments plays a specific role in the technology of risk exchange. On the one hand, financial markets allow the reallocation of resources across different dates in order to smooth consumption inter-temporally, possibly providing coverage against future risks (i.e. precautionary savings); thus, the use of financial markets is a matter of inter-temporal tradeoff. On the other hand, forest management practices are a means by which NIPF owners reallocate resources across the different states of nature and re-

\footnotetext{
${ }^{1}$ It is observed in Europe that forest insurance is an unusual practice among NIPF owners to protect their forests against natural disturbances [4].

${ }^{2}$ See for example [5] and [6] for the prevention against storm in Europe.
} 
duce their exposure to natural risks (i.e. mitigate their consequences on the rate of forest growth); thus, self-insurance decisions such as forest management practices are a matter of risk tradeoff. This gives rise to many questions. First, how do hedging strategies affect the allocation of forests to harvesting and amenity service purposes? Second, should NIPF owners use both practices simultaneously? Third, are these differences in harvesting and consumption-savings behavior dependent on the hedging strategies selected by the forest owner? Fourth, what are the qualitative properties of timber supply and hedging strategies when amenity services have private value? In this paper, we provide some answers to these questions.

These issues of forest management can be analyzed in three types of modeling framework: the basic rotation model ${ }^{3}$ the Wicksellian single rotation model ${ }^{4}$ and the two-period biomass harvesting model. ${ }^{5}$ The two-period model represents the NIPF owner's short-run decision problem, and explicitly deals with short-run timber supply rather than some state variable, such as stand age in the rotation model. This model allows for the short-run fluctuations in exogenous variables such as stumpage prices, unlike the optimal rotation model. Such variations considerably affect the forest owner's decisions. It addresses the main silvicultural practices of forest management and can be taken to represent both thinning, uneven-aged management and even-aged management with clear-cutting. It allows for risk-management decisions, consumption-savings decisions, and their implications on timber supply. The two-period model of consumption and savings offers a natural way of incorporating uncertainty and risk preferences using the expected utility framework. It also facilitates the analysis of interaction between non-timber benefits and timber ones, and implications in optimal decisions. For our purpose, the two-period model is preferred to the optimal rotation model as a more analytically suitable framework. While the effect of risk on timber supply has been studied in previous works using the two-period model ([18] ; [19]), the joint problems of smoothing consumption over time and managing a forest that simultaneously produces timber and amenities under risk have been relatively little analyzed. In the two-period model, [18] and [19] analyzed how optimal current and future harvests are affected by risk. They did not deal, however, with the issue

\footnotetext{
${ }^{3}$ The basic rotation model represents a positive description of forest owner behavior and determines a static longrun equilibrium. Empirical observations are never able to tract changes in the equilibrium harvesting levels predicted by the rotation model. It is not possible to test the theoretical predictions against empirical evidence. The reliability of policy recommendations based on the theoretical rotation framework is greatly reduced.

${ }^{4}[7],[8]$ and [9] have used the Wicksellian single rotation model to analyze the impact of inter-temporally fluctuating and stochastic mean-reverting interest rate processes on the optimal harvesting threshold and the expected length of rotation period when forest stand has been assumed to be stochastic, and landowners are risk neutral [7] and [8] or risk averse [9].

${ }^{5}[10]$ introduces a Fisherian consumption-savings model of a forest owner assumed to maximize her/his utility of consumption over two periods. This last model ([11]; [12]; [13]) has been widely used as the theoretical framework in the analysis of timber supply from NIPF owners. This model is known as the basic two-period model of timber supply analysis (see also [14]; [15]). It has been extended to include owner consumption decisions, market imperfections, non-market amenities ([12]; [16]; [17]) and taxation ([11]; [13]), and risk ([18] ; [19]).
} 
of hedging against forest risk, or the issue of consumption smoothing. To our knowledge, hedging measures against natural risks have been studied within a Faustmann rotation framework by [20] and [21] but not in a two-period biomass harvesting model.

This is our concern in this paper. We investigate decision making of NIPF owners in terms of hedging against natural hazards, and we provide a comparative analysis of the alternative advantages produced by two different hedging measures: a financial method (savings) versus a physical one (regeneration process). We explore harvesting and hedging behavior of forest owners when they value amenity services of forests, and when there is uncertainty about biological timber. The natural hazard is represented by a multiplicative risk bearing on forest growth. We show that, except when both hedging instruments are perfect substitutes, the forest owner chooses a single tool, with her/his choice depending on the rate of return of the hedging instrument. We also prove that the greater the marginal utility of amenity services, the smaller the harvesting amount. The comparative statics of current and future harvesting are developed. We show that an increase in the current (future) timber price induces a rise in first (second)-period harvesting and a decrease in second (first)-period harvesting.

The paper is organized as follows. Section 2 presents the theoretical model of timber supply when NIPF owners value the amenity services of forest stands, when there is uncertainty about production and when the owners can take hedging measures in order to protect their forest stands against natural risks. Two hedging tools are studied jointly. Section 3 explores properties of interior solutions and the results from comparative statics. Section 4 analyzes corner solutions and some extensions of the initial theoretical model. The first extension concerns the concavity of utility due to amenity functions in order to deal with the congestion problem. The second extension is about the timing of uncertainty because the final revenue of the NIPF owner depends on the realization date of such risk. Finally, Section 5 contains some concluding remarks.

\section{The model with financial and forest management practices}

\subsection{Assumptions and timing of the model}

We consider a NIPF owner who makes decisions about consumption flows ${ }^{6}$ for two periods (periods 1 and 2 hereafter). The NIPF owner is endowed with exogenous initial wealth $Y_{1}$ in period 1 and

\footnotetext{
${ }^{6}$ We assume that NIPF owners use harvesting as the decision variable. An alternative decision variable which could be used is forest stock. If NIPF owners decide upon harvesting, then consumption that depends on the revenue of forest harvest is certain whereas forest stocks will be stochastic. If they decide upon forest stocks, then the revenues of harvesting will become stochastic, and thereby consumption also. As the main objective of NIPF owners is to smooth revenue, and thereby consumption over time, it seems more realistic to consider harvesting as the decision variable.
} 
$Y_{2}$ in period 2, and an even-aged forest corresponding to an initial stock $Q$.

The timing of decisions and the description of uncertainty, named Delayed resolution of uncertainty, are represented in Figure 1, and are described as follows.

Figure 1: Timing of Decisions and Delayed resolution of uncertainty

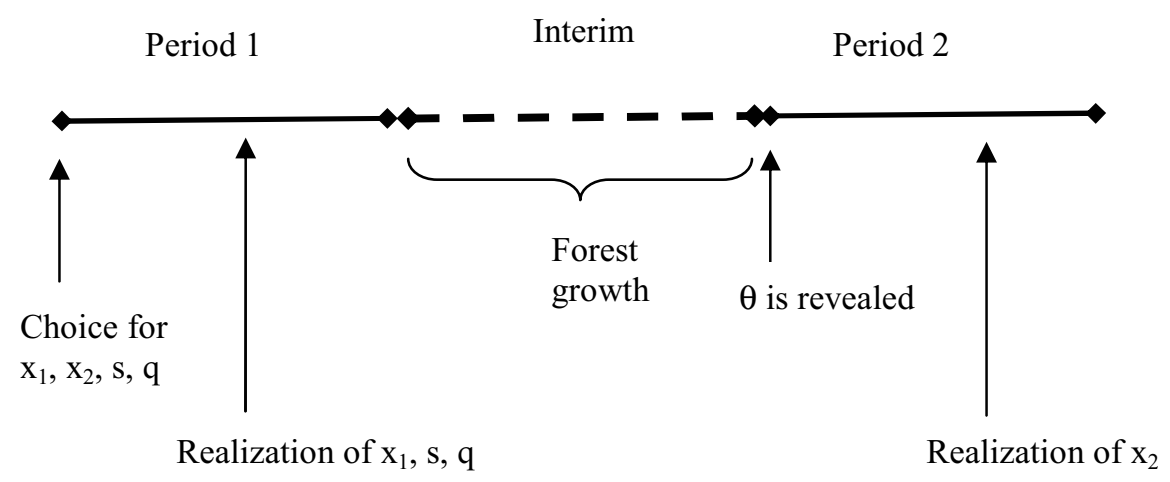

At the beginning of period 1 , the NIPF owner decides how much to harvest in the first and second periods (denoted respectively as $x_{1}, x_{2}$ ). She/he obtains timber prices denoted as $p_{1}$ and $p_{2}$, respectively. Both prices are known at the beginning of period 1, and do not depend on the timber volume supplied by the owner. We consider that the NIPF owner is a price taker. ${ }^{7}$ We also assume that there is a future timber price market which is not affected by risk occurrence. ${ }^{8}$ She/he also considers two decisions corresponding to hedging strategies. The first decision concerns financial practice, whereas the second one is about forest management practice. The financial practice is a process of savings accumulation in which the forest owner can operate on a perfect capital market and is allowed to save with no limit at a certain interest rate - we will denote as $R>1$ the gross interest rate on the capital market. The forest management practice consists, for the forest owner, in regenerating part of the forest in the first period. This regenerated part of the forest procures an outcome only in period 2 - the implicit assumption is that the young plantations produce no financial and no ecological values as long as they have not yet reached a sufficient size, which only occurs in the second period. The stock of regenerated trees is not affected by the occurrence of natural disaster events, such that the value of the regenerated forest stock in the second period does not depend on the realization of the random variable. Such a physical practice can be seen as a precautionary means of protecting the forest against natural risks. Investment in the regeneration

\footnotetext{
${ }^{7}$ For small NIPF owners, stumpage prices do not depend on the volume harvested.

${ }^{8}[18]$ considered that there was uncertainty about future timber price but not about future timber stock.
} 
process is represented through a constitution cost in period 1, denoted $c(q)$ where $c(q)=c . q$ and $c>0$, and $q$ represents the stock of regenerated trees chosen by the forest owner.

At the time the NIPF owner takes her/his decisions, she/he observes the present and future values for harvesting prices at each date and the various technological parameters, except for the value of the forest stand at the beginning of period 2. This is because, during an interim period, the final first period forest stock $k_{1}$ (i.e. after the realization of the first-period harvesting) evolves according to a process described through the function $g\left(k_{1}\right)$ satisfying: $g(0)=0$, and for any $k_{1}>0$ : $g^{\prime}>1$ and $g^{\prime \prime}<0$. However, the final outcome of this (natural) process depends on the realization of a random variable, reflecting the influence of some natural risks (biological or climatic) affecting the value of the forest stock at the beginning of period 2 and before the implementation of the harvesting decision for period 2 .

Uncertainty is described through the random variable $\theta$, and the value of $\theta$ is resolved at the end of the growth process. In other words, $\theta$ is revealed and observed by the forest owner only at the beginning of period 2, but without having the opportunity beforehand to make her/his second period harvesting decision, such that the value of the stands at the end of the growth process and before that harvesting takes place is $\theta g\left(k_{1}\right)$. The possible realizations for $\theta$ are described according to a probability distribution which is supposed to be known by the forest owner at the beginning of period 1 , and represented by a cumulative function denoted $F(\theta)$ defined on $[\underline{\theta}, \bar{\theta}] \subset[0,1]$ and with a density $f(\theta)>0$ everywhere. Remark that we may choose $\underline{\theta}$ as close as possible to 0 , which may be seen as the realization of a catastrophic event implying that the forest is fully destroyed. In this case, any harvesting decision $x_{2}>0$ set in period 1 appears not to be feasible. In contrast, as $\theta \rightarrow 1$, the event corresponds to the best outcome for the NIPF owner, when no natural risk damages the forest property. However, the paper does not elaborate on the issue of contingent plans for harvesting in period 2 - we will consider only the situation where the forest owner voluntarily makes dynamically consistent choices.

The forest owner's preferences are defined, on the one hand, on the basis of her/his present and past consumption, denoted as $c_{1}$ and $c_{2}$ respectively, and on the other hand, of present and future amenity services provided by forest stands, denoted as $k_{1}$ and $k_{2}$, respectively. ${ }^{9}$ For the sake of simplicity, we will assume that such preferences have a representation which is additively separable both between periods, and between consumption and amenity services at each date, such that for a given inter-temporal flow of consumption and forest stands $\left(c_{1}, c_{2}, k_{1}, k_{2}\right)$ the associated utility level $V$ is defined by:

\footnotetext{
${ }^{9}$ We introduce the traditional assumption in which non-timber services are a function of the standing stock volume $[22]$.
} 


$$
V=u\left(c_{1}\right)+v\left(k_{1}\right)+\delta\left[u\left(c_{2}\right)+v\left(k_{2}\right)\right]
$$

where $\delta \in] 0,1[$ is the discounting factor, $u$ is the temporal utility function for consumption, and $v$ is the temporal utility function for amenity services. We will assume that $u$ is increasing and concave $\left(u^{\prime}>0, u^{\prime \prime}<0\right)$, while $v$ satisfies $v^{\prime}=m=$ constant $>0$. This last assumption ${ }^{10}$ seems of specific concern here, since we introduce only pure individual amenities, and not collective ones: the forest owner has the opportunity to enjoy the existence of amenity services provided by the forest, without incurring a congestion externality effect as in the case of collective use of forest. For example, when the owner contemplates a beautiful landscape, her/his marginal utility from amenities is constant. However, if ten persons arrive, block owner's view and make some noise, then the constant marginal utility hypothesis does not hold. Consequently, this assumption can be justified for amenity services for which congestion is not a relevant issue. This could apply to scenic beauty or recreation.

When the forest owner has the opportunity to accumulate savings and, at the same time, to invest in the regeneration process, the forest owner's inter-temporal consumption decisions must respect two basic temporal budget constraints:

$$
\begin{aligned}
& c_{1} \equiv Y_{1}+\pi\left(x_{1}\right)-s-c . q \text { with } \pi\left(x_{1}\right) \equiv p_{1} x_{1}-h\left(x_{1}\right) \\
& c_{2} \equiv Y_{2}+R . s+\pi\left(x_{2}\right) \text { with } \pi\left(x_{2}\right) \equiv p_{2} x_{2}-h\left(x_{2}\right)
\end{aligned}
$$

where $\pi\left(x_{i}\right)$ for $i=1,2$ denotes the net benefit from the harvesting in period $i$, which is defined as usual as the difference between harvesting revenue $p_{i} x_{i}$ and harvesting cost $h\left(x_{i}\right)$ corresponding to the various expenditure borne by the landowner during the harvesting process; we will assume that $h\left(x_{i}\right)=h x_{i}$ with $h>0$. Note that (2) and (3) concern the forest owner's consumption and savings decisions. In the first period, consumption $\left(c_{1}\right)$ is defined by the sum of initial wealth $\left(Y_{1}\right)$ and the net revenue from harvesting minus savings $(s)$ and regeneration cost $c q$. During the first period, the forest owner allocates the total revenue between current consumption, savings and risk forest-management cost. In the second period, consumption $\left(c_{2}\right)$ is represented by the sum of initial wealth $\left(Y_{2}\right)$ and net revenue from harvesting and earnings on savings $(R s)$.

The joint production of timber and amenities is defined by the two following relationships, and the associated feasibility constraints:

\footnotetext{
${ }^{10}[18]$ also considered constant marginal utility in terms of amenity services.
} 


$$
\begin{aligned}
k_{1} & \equiv Q-x_{1}, \text { with } 0 \leq x_{1} \leq Q \\
k_{2}(\theta) & \equiv \theta g\left(Q-x_{1}\right)-x_{2}+q, \text { with } 0 \leq x_{2} \leq \underline{\theta} \cdot g\left(Q-x_{1}\right)+q
\end{aligned}
$$

According to (4), the value of the stand at the end of period 1 and before the beginning of the interim period, is the difference between initial forest stock $Q$ and the first-period harvesting $x_{1}$. Thus, it may be useful to consider some natural restrictions such as $0 \leq x_{1} \leq Q$ which introduce some obvious limits into the first harvesting decision: the landowner may prefer not to harvest at all in the first period, or on the contrary to harvest all the available timber; both restrictions imply, given the forest owner's intrinsic preferences for amenity services, that: $k_{1} \geq 0$. According to (5) now, ${ }^{11}$ the value of the forest stands at the end of period 2 is the difference between the value of the available stands after the realization of $\theta$, and the second-period harvesting. We also have to consider some natural restrictions: the landowner may prefer not to harvest for the second period: thus $0 \leq x_{2}$. However, to the extent that the harvesting decision for period 2 is made at the beginning of period 1 - and thus, without knowing the realized value of $\theta$ - the landowner may experience some trouble in period 2 when confronted with a decision that cannot be implemented. This occurs when/because the owner decided ex ante for a high level of $x_{2}$, but unfortunately it appears as non-feasible ex post given a low realization of $\theta$ for example: i.e. $\theta g\left(Q-x_{1}\right)<x_{2} \Rightarrow k_{2}(\theta)<0$. In order to overcome the difficulties arising from the occurrence of such dynamically inconsistent decisions, it is natural to assume that the NIPF owner considers the worst state of nature and adopts a disciplined approach (precautious, reasonable, or self-restrained behavior), such as not harvesting for more than the surviving stands after the lowest value of $\theta$ is realized. Such discipline implies, for example, that $k_{2}(\theta) \geq 0$ for any $\theta$ - and when the constraint binds (the owner decides in period 1 on the highest possible harvesting in period 2) then $k_{2}(\underline{\theta})=0$ but $k_{2}(\theta)>0$ for any $\theta>\underline{\theta}$.

\subsection{Optimal rules of financial and physical practices}

One of the main purposes of the paper is to analyze two different strategies allowing the management of forest risks, when these risks are the sole source of uncertainty. In other words, both instruments are designed to fulfill the same objective in the economy, and both have perfectly foreseen outcomes in the second period. In particular, they have a deterministic influence in the sense that their use

\footnotetext{
${ }^{11}$ The literature usually assumes that $k_{2}=k_{1}+h\left(k_{1}\right)-x_{2}=k_{1}\left(1+\frac{h\left(k_{1}\right)}{k_{1}}\right)-x_{2}$ where $h($.$) is an increasing and$ concave function (see [18] ; [19]; [23]), such that $\frac{h\left(k_{1}\right)}{k_{1}}$ corresponds to the net forest growth rate. Remark that both specifications are equivalent to the extent that $\frac{g\left(k_{1}\right)}{k_{1}}=1+\frac{h\left(k_{1}\right)}{k_{1}}$ corresponds to the gross forest growth rate. Our formulation simply allows more tractable expressions for the first order conditions.
} 
entails no additional source of uncertainty for the NIPF owner: the interest rate and the cost of physical practice are known with certainty. As a result, the landowner can use two instruments which are close substitutes, differing only in terms of return/cost conditions. The issue is thus: Should the forest owner use both instruments? We show that generally this is not the case.

Formally, the NIPF owner makes four decisions at the beginning of period $1\left(x_{1}, x_{2}, s, q\right)$ in order to maximize the expectation of (1) under constraints (2) to (5). The decision program of the forest owner is the following, which explicitly deals with the non-negativity constraints on $q$ and $s$ :

$$
P 1\left\{\begin{array}{cl}
\operatorname{Max}_{\left\{x_{1}, x_{2}, s, q\right\}} & u\left(c_{1}\right)+m k_{1}+\delta\left[u\left(c_{2}\right)+m E\left(k_{2}(\theta)\right)\right] \\
s / t & =Y_{1}+\pi\left(x_{1}\right)-s-c(q) \text { with } \pi\left(x_{1}\right) \equiv p_{1} x_{1}-h\left(x_{1}\right) \\
c_{1} & =Y_{2}+R . s+\pi\left(x_{2}\right) \text { with } \pi\left(x_{2}\right) \equiv p_{2} x_{2}-h\left(x_{2}\right) \\
c_{2} & Q-x_{1}, \text { with } 0 \leq x_{1} \leq Q \\
k_{1} & =9 g\left(Q-x_{1}\right)-x_{2}+q, \text { with } 0 \leq x_{2} \leq \underline{\theta} . g\left(Q-x_{1}\right)+q \\
k_{2}(\theta) & \geq \\
q & \geq
\end{array}\right.
$$

Given the high number of associated constraints which may potentially be involved, we will introduce some simplifications in order to focus on the main issues of the model. To begin with, we may easily deal with, and thus neglect the non-negativity constraints on $x_{1}$ and $x_{2}$ (i.e. we will assume that $0<x_{1}$ and $0<x_{2}$ ). Intuitively, this requires $p_{1}$ and $p_{2}$ to be large enough. For example it can be verified that $p_{1}>h+{\frac{m}{u^{\prime}\left(Y_{1}\right)}}_{1}\left(1+E(\theta) \cdot g^{\prime}(Q)\right) \Rightarrow{\frac{d E V}{d x_{1}}}_{\mid x_{1}=s=q=0}>0$ and $p_{2}>h+\frac{m}{u^{\prime}\left(Y_{2}\right)} \Rightarrow \frac{d E V}{d x_{2}}{\mid x_{2}=s=0}>0$, justifying that at least some harvesting is undertaken at each date. Note that this also implies that $p_{i}-h>0$ is not enough to have $x_{i}>0$ for all $i=1,2: p_{1}$ and $p_{2}$ must be sufficiently greater than the marginal cost $h$. We will consider that such conditions hold in the rest of the paper.

This allows us to focus on the issue of the optimal mix $(q, s)$ under the feasibility constraints on harvesting in both periods. Let us introduce four Lagrange multipliers: $\mu, \lambda, \gamma, \sigma$, such that:

- $\mu=0$ if $s>0$ and otherwise $\mu \geq 0$;

- $\lambda=0$ if $q>0$ and otherwise $\lambda \geq 0$;

- $\sigma=0$ if $x_{1}<Q$ and otherwise $\sigma \geq 0$;

- $\gamma=0$ if $x_{2}<\underline{\theta} g\left(Q-x_{1}\right)+q$ and otherwise $\gamma \geq 0$. 
The first order conditions defining the solutions for (P1) are the following ones: ${ }^{12}$

$$
\begin{aligned}
\pi_{1}^{\prime} u_{1}^{\prime}-m\left(1+\delta g^{\prime} \cdot E(\theta)\right)-\sigma-\delta \gamma \underline{\theta} g^{\prime} & =0 \\
\delta\left(\pi_{2}^{\prime} u_{2}^{\prime}-m\right)-\gamma & =0 \\
-u_{1}^{\prime}+\delta R u_{2}^{\prime}+\mu & =0 \\
-c u_{1}^{\prime}+(\delta m+\gamma)+\lambda & =0
\end{aligned}
$$

where $\pi_{i}^{\prime}=\pi_{i}^{\prime}\left(x_{i}\right)=p_{i}-h$ for $i=1,2$. For an analysis of the second order conditions, see Appendix A; these are met under the concavity restriction introduced on functions $u$ and $g$. Remark that (6) is written as $\pi_{1}^{\prime} u_{1}^{\prime}=m\left(1+\delta g^{\prime} . E(\theta)\right)+\sigma+\delta \gamma \underline{\theta} g^{\prime}$; given that the RHS term in the equality is positive, this implies that $\pi_{1}^{\prime}=p_{1}-h>0$. By a similar argument, note that (7) is also written as $\delta \pi_{2}^{\prime} u_{2}^{\prime}=\delta m+\gamma$ which yields $\pi_{2}^{\prime}=p_{2}-h>0$. Note that these restrictions are obviously satisfied once we introduce the (necessary) conditions that both prices are high enough as seen before.

The central result regarding the optimal use of savings and silvicultural practices is afforded by the Proposition 1:

Proposition 1 All else held equal:

i) If $R>\frac{p_{2}-h}{c}$ then the solution is such that $s^{*}>0$ and $q^{*}=0$.

ii) If $R<\frac{p_{2}-h}{c}$ then the solution is such that $q^{*}>0$ and $s^{*}=0$.

iii) If $R=\frac{p_{2}-h}{c}$ then the optimal mix of $q^{*}>0$ and $s^{*}>0$ is undetermined.

Proof. Mixing (7) and (8) leads to: $u_{1}^{\prime}=\frac{R}{\pi_{2}^{\prime}}(\delta m+\gamma)+\mu$, while equation (9) yields: $u_{1}^{\prime}=$ $\frac{1}{c}(\delta m+\gamma)+\frac{\lambda}{c}$. Mixing both relationships and using (7) gives: $\delta u_{2}^{\prime}\left(R-\frac{\pi_{2}^{\prime}}{c}\right) m=\frac{\lambda}{c}-\mu$, implying that any solution is such that:

$$
\operatorname{sign}\left(R-\frac{\pi_{2}^{\prime}}{c}\right)=\operatorname{sign}\left(\frac{\lambda}{c}-\mu\right)
$$

Consequently, there are three possibilities:

$1 /$ if $R-\frac{\pi_{2}^{\prime}}{c}<0$ then $\frac{\lambda}{c}<\mu$ and it is impossible that $s>0$. Indeed, $s>0$ implies $\mu=0$ and this requires that $\lambda<0$, which is a contradiction. $\lambda$ could be equal to zero but then, equations (7) and (8) bring a new contradiction $R=\frac{\pi_{2}^{\prime}}{c}$. Thus, the sole solution is $s=0$ and $q>0$.

\footnotetext{
${ }^{12}$ To clarify the presentation of these conditions, we simplify the writing of the functions by not clarifying the variables which compose them.
} 
$2 /$ if $R-\frac{\pi_{2}^{\prime}}{c}>0$ then $\frac{\lambda}{c}>\mu$ and it is impossible that $q>0$. Indeed, $q>0$ implies $\lambda=0$ and this requires that $\mu<0$, which is a contradiction. Consequently, the only solution is $s>0$ and $q=0$.

$3 /$ if $R-\frac{\pi_{2}^{\prime}}{c}=0$ then $\frac{\lambda}{c}=\mu$ and this requires that, either $s=0$ and $q=0$ (but we ignore such a corner solution), or $s>0$ and $q>0$. But, intuitively, when $s>0$ and $q>0, q$ and $s$ are redundant because (8) and (9) with $R=\frac{\pi_{2}^{\prime}}{c}$ and $\mu=\frac{\lambda}{c}=0$ give the following condition: $\delta R u_{2}^{\prime}=\delta \frac{1}{c} m \Rightarrow \pi_{2}^{\prime} u_{2}^{\prime}=m$ which means that one of the conditions (7), (8) or (9) is redundant.

The results of Proposition 1 mean that, under our technological assumptions (i.e. constant marginal costs for both harvesting and silvicultural practice), the landowner uses the financial practice if it represents the best return/cost condition compared to the silvicultural one (namely: $R>\frac{\pi_{2}^{\prime}}{c}$ ), or she/he only uses silvicultural practice in the opposite case (when: $R<\frac{\pi_{2}^{\prime}}{c}$ ). But if $R=\frac{\pi_{2}^{\prime}}{c}$, the forest owner is facing two perfectly substitutable instruments in relation to which she/he is indifferent; in this case, she/he may use only one of the instruments, or any mix of both. This allows us, in the next paragraph, to focus on situations where the landowner only chooses a single practice, and we analyze the general properties of harvesting decisions.

\subsection{Optimal harvesting decisions : pure interior solutions}

Here, we concentrate on the interior solutions for optimal harvesting decisions in the first and second periods. Note that whatever the specification of the model, the second-period harvesting rule is restricted in order to maintain dynamically consistent decisions. The NIPF owner is assumed not to harvest more than the surviving stands after the lowest value of $\theta$ is realized. We forward to the last section of the paper the analysis of the solution where the feasibility constraint on second period harvesting binds.

\subsubsection{Harvesting decisions in the savings model}

First, let us assume that the financial practice has a higher return/cost ratio than the silvicultural one (i.e. $R-\frac{\pi_{2}^{\prime}}{c}>0$ ). Therefore the landowner only uses savings to reallocate resources between the two periods. Formally, the decision program of the forest owner is described by (P1) with $q=0$, and will be termed the "savings model" in the rest of the paper.

In this case, let us denote the optimal choice as $\left(x_{1}^{*}, x_{2}^{*}, s^{*}\right)^{13}$. Using conditions (6), (7) and (8),

\footnotetext{
${ }^{13}$ We focus on solutions where $s>0$, thus requiring that the conditions for $\frac{\partial E V}{\partial s}_{\mid s=0}>0$ are satisfied; basically, this is the case if we introduce the restriction that $R>\frac{u^{\prime}\left(Y_{1}\right)}{\delta u^{\prime}\left(Y_{2}\right)}$ which is usual in savings models.
} 
the first order conditions for a (interior) solution with $s>0, x_{1}>0$ and $x_{2}<\underline{\theta} . g\left(Q-x_{1}\right)$ are given simply by the next three equations (since $\mu=\sigma=\gamma=0$ and condition (9) is irrelevant in the sense that it gives only $\lambda>0$ ):

$$
\begin{aligned}
& (A) \quad: \quad \pi_{1}^{\prime} \cdot u_{1}^{\prime}=m\left(1+\delta g^{\prime} \cdot E(\theta)\right) \\
& (B) \quad: \quad \pi_{2}^{\prime} \cdot u_{2}^{\prime}=m \\
& (C) \quad: \quad u_{1}^{\prime}=\delta R u_{2}^{\prime}
\end{aligned}
$$

Condition $(\mathrm{C})$ is the common inter-temporal arbitrage condition, saying that savings are set in order to make the marginal rate of substitution between current and future consumption and the gross interest rate equal. Condition (B) means that the optimal second-period harvesting rule is reached when the marginal benefits of harvesting expressed in utility terms $\left(\pi_{2}^{\prime} u_{2}^{\prime}\right)$ are equal to its marginal cost corresponding to the decrease in amenity services $(m)$. Finally, condition (A) now shows that the first-period harvesting rule makes the value of the marginal benefits in utility terms $\left(\pi_{1}^{\prime} u_{1}^{\prime}\right)$ associated with harvesting proceeds equal to the value of its (composite) marginal cost $\left(m\left(1+\delta g^{\prime} . E(\theta)\right)\right)$, since harvesting more in the present period reduces the value of the first-period amenity services, but also reduces the expected outcome of the natural growth process for the forest between the two periods.

Rearranging (B) and (C) yields respectively $u_{1}^{\prime}=\frac{\delta R}{\pi_{2}^{\prime}} m$ and $u_{2}^{\prime}=\frac{m}{\pi_{2}^{\prime}}$, and then substituting in (A), we can write the system (A)-(B)-(C) as follows:

$$
\begin{aligned}
& \left(A^{\prime}\right): \quad g^{\prime}=\frac{1}{E(\theta)} \cdot\left(R \frac{\pi_{1}^{\prime}}{\pi_{2}^{\prime}}-\frac{1}{\delta}\right) \\
& \left(B^{\prime}\right) \quad: \quad u_{2}^{\prime}=\frac{m}{\pi_{2}^{\prime}} \\
& \left(C^{\prime}\right) \quad: \quad u_{1}^{\prime}=\delta R \frac{m}{\pi_{2}^{\prime}}
\end{aligned}
$$

These conditions call for two remarks. First, note that according to (A'), a necessary condition required for a solution with $x_{1}>0$ is that $R \frac{\pi_{1}^{\prime}}{\pi_{2}^{\prime}}>\frac{1}{\delta}$. Second, given our technological assumptions and given (2), (3), (4) and (5), we obtain a hierarchical resolution of this system: the period 1 harvesting decision is obtained thanks to condition ( $\left.\mathrm{A}^{\prime}\right)$, then the optimal savings amount is given by (C') and, finally, condition (B') yields the period 2 harvesting rule.

Proposition 2 summarizes our findings: 
Proposition 2 In the savings model, assume that $R \frac{\pi_{1}^{\prime}}{\pi_{2}^{\prime}}>\frac{1}{\delta}$; in a pure interior solution, the period 1 harvesting rule satisfies:

$$
g^{\prime}\left(Q-x_{1}^{*}\right)=\frac{1}{E(\theta)} \cdot\left(R \frac{\pi_{1}^{\prime}}{\pi_{2}^{\prime}}-\frac{1}{\delta}\right)
$$

and the period 2 harvesting rule satisfies the following condition:

$$
u_{2}^{\prime}\left(Y_{2}+R \cdot s^{*}+\pi\left(x_{2}^{*}\right)\right)=\frac{m}{\pi_{2}^{\prime}}
$$

with a $s^{*}>0$ satisfying $\left(C^{\prime}\right)$.

\subsubsection{Harvesting decisions in the silvicultural practice model}

Second, let us assume that the higher return/cost ratio is for the forest management practice (i.e. $\left.R-\frac{\pi_{2}^{\prime}}{c}<0\right)$; then the NIPF owner implements this approach. Formally, the decision program of the forest owner is now described by (P1) with $s=0$, and it will be termed the "silvicultural practice model" in the rest of the paper. The NIPF owner makes three decisions $\left(x_{1}, x_{2}, q\right)$ at the beginning of period 1 in order to maximize her/his inter-temporal satisfaction level.

In the silvicultural practice model, let us denote the optimal choice as $\left(x_{1}^{*}, x_{2}^{*}, q^{*}\right)^{14}$. Once more, using conditions (6), (7) and (9), the first order conditions for an interior solution with $q>0, x_{1}>0$ and $x_{2}<\underline{\theta} . g\left(Q-x_{1}\right)+q$ (since $\sigma=\lambda=\gamma=0$ and condition (8) is now irrelevant in the sense that it only gives $\mu$ ) are:

$$
\begin{aligned}
(H) & : \quad \pi_{1}^{\prime} \cdot u_{1}^{\prime}=m\left(1+\delta g^{\prime} \cdot E(\theta)\right) \\
(I) \quad: & \pi_{2}^{\prime} \cdot u_{2}^{\prime}=m \\
(J) & : \quad c u_{1}^{\prime}=\delta m
\end{aligned}
$$

It is obvious that the system is formally close to the one defined by $(A)-(B)-(C)$, except with respect to the last condition. Thus using (I) and (J) in (H), we may now substitute system (H)-(I)-(J) with:

\footnotetext{
${ }^{14}$ Once more, we focus on solutions where $q>0$, thus requiring that the conditions for $\frac{\partial E V}{\partial q}_{\mid q=0}>0$ are satisfied; basically, this is the case if we assume that the marginal cost of silvicultural practices is low enough, such that: $c<\frac{\delta m}{u^{\prime}\left(Y_{1}\right)}$. Note that more generally speaking, any model with self-protection activities usually considers such a restriction.
} 


$$
\begin{aligned}
&\left(H^{\prime}\right): g^{\prime}=\frac{1}{E(\theta)} \cdot\left(\frac{\pi_{1}^{\prime}}{c}-\frac{1}{\delta}\right) \\
&\left(I^{\prime}\right):: \quad u_{2}^{\prime}=\frac{m}{\pi_{2}^{\prime}} \\
&\left(J^{\prime}\right) \quad: \quad u_{1}^{\prime}=\delta \frac{m}{c}
\end{aligned}
$$

This also suggests at least that the same comments apply here regarding the resolution of the model. First, note that a necessary condition required to have $x_{1}>0$ is that now $\frac{\pi_{1}^{\prime}}{c}>\frac{1}{\delta}$. Second, the period 1 harvesting decision is obtained directly using condition ( $\left.\mathrm{H}^{\prime}\right)$ while silvicultural practices are given by $\left(\mathrm{J}^{\prime}\right)$ and the second-period harvesting decision is given by (I').

Proposition 3 summarizes our findings:

Proposition 3 In the silvicultural practice model, assuming that $\frac{\pi_{1}^{\prime}}{c}>\frac{1}{\delta}$; in a pure interior solution, then the period 1 harvesting rule satisfies:

$$
g^{\prime}\left(Q-x_{1}^{*}\right)=\frac{1}{E(\theta)} \cdot\left(\frac{\pi_{1}^{\prime}}{c}-\frac{1}{\delta}\right)
$$

and the period 2 harvesting rule satisfies the following condition:

$$
u_{2}^{\prime}\left(Y_{2}+\pi\left(x_{2}^{*}\right)\right)=\frac{m}{\pi_{2}^{\prime}}
$$

with a $q>0$ given by $\left(J^{\prime}\right)$.

\subsubsection{Comparison}

The comparison between the savings and silvicultural practice models yields a first consequence which is that:

Corollary 4 The silvicultural practice model leads to a larger amount of harvesting in the second period than the savings model, all else held equal.

Proof. Simply given that for all $x_{2}>0$ and any $s>0$ then $Y_{2}+R . s+\pi\left(x_{2}\right)>Y_{2}+\pi\left(x_{2}\right)$; thus by the concavity of $u$, we obtain $u^{\prime}\left(Y_{2}+R . s+\pi\left(x_{2}\right)\right)<u^{\prime}\left(Y_{2}+\pi\left(x_{2}\right)\right)$ : this implies that for any value of $x_{2}$ the Left Hand Side (LHS) in (11) is smaller than the LHS in (13). As a result, given that both LHS are decreasing functions in $x_{2}$, while in addition both RHS in (11) and (13) are identical and constant (they do not depend on $x_{2}$ ), then the equilibrium value for $x_{2}$ is smaller 
in (11) than in (13).

In contrast, note that a direct comparison of first-period harvesting decisions between the two models does not really make sense. However, it is worth noting that there is a positive relationship between $x_{1}$ and $\left(\frac{R \pi_{1}^{\prime}}{\pi_{2}^{\prime}}-\frac{1}{\delta}\right)$ in the savings model, or $\left(\frac{\pi_{1}^{\prime}}{c}-\frac{1}{\delta}\right)$ in the silvicultural practice one: this leads to the intuition of the functioning of both models, which runs as follows. When $R>\frac{\pi_{2}^{\prime}}{c}$, then comparing (10) and (12) shows that the NIPF harvests more in the first period when he accumulates savings than when he undertakes silvicultural practices; then, the savings enable them to transfer a part of the first-period harvesting proceeds in the future in order to finance more consumption in the future, although the NIPF harvests less at this date. On the contrary, when $R<\frac{\pi_{2}^{\prime}}{c}$, the comparison between (10) and (12) now shows that the NIPF harvests more in the first period when she/he undertakes silvicultural practices than when she/he accumulates savings. Then, the harvesting proceeds are used to finance silvicultural practices, which allow for more forest growth; this gives the opportunity to harvest more in the future in order to finance more consumption at this date.

Thus, depending on the sign of $R-\frac{\pi_{2}^{\prime}}{c}$, our results simply suggest that the NIPF makes decisions which yield the most efficient strategy in terms of consumption smoothing.

Now, putting together the results of Propositions 1 to 3, we obtain a second interesting consequence which is that both instruments may in fact have equivalent consequences in terms of consumption smoothing. Consider two different economies, having the same characteristics in terms of the value of $\delta, p_{1}, p_{2}$ and the technological parameters such as the forest growth process $g$, probability distribution $F(\theta)$ and cost function $h$. In the first economy, forest owners have access to a perfect financial market paying a gross interest rate $R$. In the second one, forest owners have no access to a capital market, but invest in a costly regeneration process at a marginal cost $c$. Then, if the ratio of the period 2 marginal profit to the marginal cost of silvicultural practice is constant and satisfies $\frac{\pi_{2}^{\prime}}{c}=R$, then in both economies forest owners reach the same inter-temporal consumption profile, choose the same harvesting rules and obtain the same value for amenity services.

An alternative way of interpreting this result may be obtained if we write $R=\frac{\pi_{2}^{\prime}}{c}$ as $\frac{p_{2}}{R}=\frac{h}{R}+c$, and consider that public authorities regulate the timber price market. As a result, assuming that all NIPF have the same technology for harvesting and for silvicultural practices:

Corollary 5 Let us define as $\hat{p}=h+$ R.c. Then, if the regulator sets $p_{2}>\hat{p}$ any forest owner will invest in silvicultural rather than in financial practice; in contrast, if the regulator sets $p_{2}<\hat{p}$ any forest owner will accumulate savings rather than investing in regeneration process. 
We have seen before that $\hat{p}=h+R c$ is the second-period timber price market for which the NIPF is indifferent between savings and silvicultural practice strategy. Thus, raising (lowering) $p_{2}$ above (respectively, under) $\hat{p}$ gives incentives to a NIPF to choose the savings strategy (respectively, silvicultural practices).

Note that the same kind of intuition is obtained when public authorities are assumed to subsidise the silvicultural practices, thus defining as $\hat{c}=\frac{\pi_{2}^{\prime}}{R}$ the marginal cost for silvicultural practices for which the NIPF is indifferent between savings and silvicultural practice strategy. If public authorities allocate a subsidy to NIPF such that $c<\hat{c}$, then any one will prefer silvicultural practices to accumulating savings; but in contrast, if the subsidy is not large enough such that $c>\hat{c}$, then any NIPF will prefer to accumulate savings rather than undertaking silvicultural practices.

\section{Properties of pure interior solutions}

\subsection{Mitigation effects of amenity services}

In this paragraph, we analyze the impact of the value of amenity services on optimal harvesting decisions, and also on financial or physical practice.

Proposition 6 A) In the savings model, the first-period harvesting amount does not depend on the level of amenity services; on the contrary, all else held equal, the larger the marginal utility of amenity services, the smaller the second-period harvesting amount, but the larger the savings.

B) In the silvicultural practice model, the first-period harvesting amount does not depend on the level of amenity services; on the contrary, all else held equal the larger the marginal utility of amenity services, the smaller the second-period harvesting amount, but the larger the silvicultural practices.

Proof. A) Regarding the fact that the first-period harvesting rule does not depend on $m$, this is obvious using (10). Now, given that the LHS in (11) is a decreasing function of $x_{2}$ (and also of $s$ ) and that the LHS in (C') is increasing in $s$, it is easy to verify that an increase in $m$ leads to a decrease in $x_{2}$ but an increase in $s$.

B) The same arguments apply for the silvicultural practice model using (12), (13) and (J) (except that the LHS in (13) does not depend on $q$ ). 


\subsection{Other comparative static results}

Table 1 summarizes the set of comparative static results for an interior solution. The proof of these results is given in Appendix B for the savings model, and is available from the authors for the physical practice model.

Table 1: Comparative static results

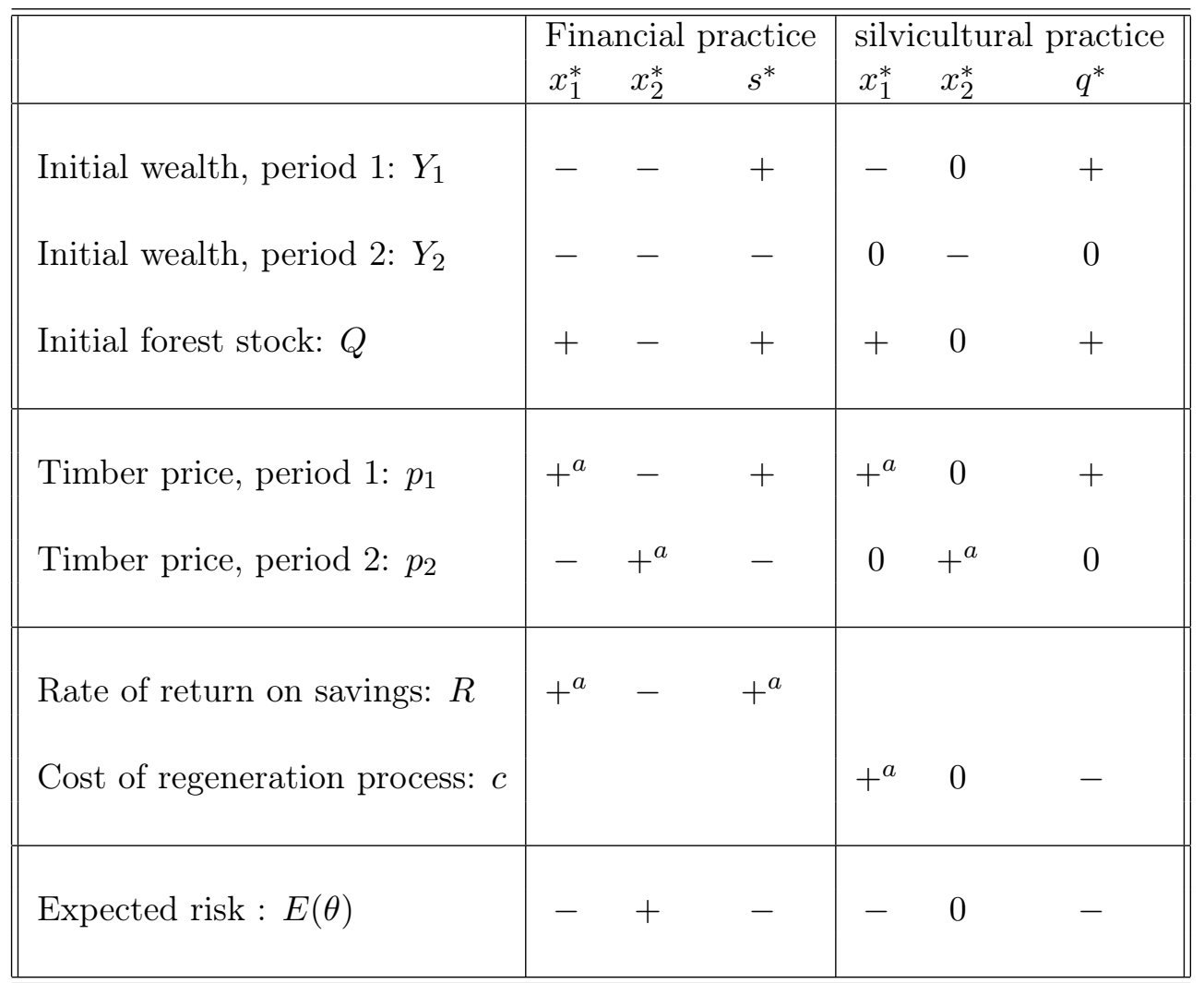

${ }^{a}$ These results are obtained if the partial risk aversion coefficient is less than 1 otherwise ambiguous results emerge.

A major difference appears between the two instruments. The comparative static results for the silvicultural practice model show a lot of zero values, i.e. several parameters have no effect on the decision variables $\left(x_{1}, x_{2}\right.$ or $\left.q\right)$, as compared to the savings model. This difference is due to our assumption concerning the utility afforded by amenity services. Indeed, the savings decision acts on the utility of second-period consumption, assuming as usual a decreasing marginal utility $u^{\prime \prime}<0$. In contrast, the silvicultural practices (regeneration process) act on the utility of future amenity services, which is supposed to satisfy the constant marginal utility assumption: $v^{\prime}()=.m>0$ and $v^{\prime \prime}=0$. We will relax this assumption later on. 
- Income and stock effects

Our results concerning the impact of an increase in first-period income $Y_{1}$ and initial forest stock $Q$ on decisions about protection instruments are traditional. We find positive income/stock effects for $s$ and $q$. This result means that savings and regeneration process are superior goods. Concerning an increase in $Y_{2}$, the effect on the accumulation of savings $s$ is negative, due to the fact that the forest owner anticipating an increase in her/his second-period income decides to reduce savings in period 1 in order to keep the consumption level constant in period 2.

\section{- Price effects}

An increase in the wood price in the first period leads to an increase in the first-period harvesting and in the use of savings and the regeneration process as a means of protecting against natural disasters. We observe positive price effects on savings and the regeneration process. The impact of an increase in first-period prices on first-period harvest can be broken down into two effects: a negative income effect $\left(\frac{d x_{1}}{d Y_{1}}<0\right)$ and a positive substitution one. The use of the partial risk aversion coefficient allows us to assert that, if this coefficient is smaller than 1 , then the substitution effect is greater than the income one, so the forest owner increases first-period harvesting to be wealthier. The higher level of income allows the owner to reduce second-period harvesting, while keeping her/his second-period consumption constant, as we observed for savings. An increase in first-period price gives the owners incentives to adopt savings or the regeneration process. Consequently, the implementation of minimum prices for wood products may guarantee the owners that the wood prices will not fall below this threshold. This artificial support may prevent prices from collapsing.

An increase in the wood price in the second period reduces the first-period harvesting and the recourse to financial practice for the savings model, while these two effects are null for the silvicultural practice model. The impact of an increase in second-period price on second-period harvesting is positive for savings and the regeneration process. We have a negative income effect $\left(\frac{d x_{2}}{d Y_{2}}<0\right)$ and a positive substitution one. If the partial risk aversion coefficient is less than 1 , then the substitution effect dominates the income effect, so owners increase second-period harvesting.

\section{- Opportunity cost effects}

Table 1 shows that the impact of an increase in the rate of return on savings is positive on first- 
period harvesting and the accumulation of savings, while this effect is negative on second-period harvesting. Although these two effects are opposite (negative income effect and positive substitution one), if the partial risk aversion coefficient is less than 1, we can report that when forest revenue rises, owners increase first-period harvest in order to be wealthier.

The effect of an increase in the cost of the regeneration process on first-period harvesting is positive if the partial risk aversion coefficient is less than 1, null on the second-period harvest and finally, negative on the use of the silvicultural practice. As the cost rises, the owners reduce the stock of regenerated trees, because it becomes more and more expensive for them to regenerate a part of the forest.

\section{- Risk effect}

Given that the objective function in (P1) is linear in $\theta$, any increase in the risk affecting the probability density function of $\theta$, either in the first stochastic dominance or second stochastic dominance sense, simply yields a decrease in $E(\theta)$. Consequently, we conduct our static comparative analysis of a shift in risk focusing directly on an increase in $E(\theta)$.

We observe that an increase in $E(\theta)$ reduces first-period harvest and the recourse to savings or regeneration. We also remark that an increase in $E(\theta)$ generates an increase in second-period harvesting. The information about $\theta$ was revealed at the beginning of second period, so when the owners learn that $E(\theta)$ is higher, they increase second-period harvesting in order to reduce the potential losses in case of disaster.

To conclude, except for the null effects of comparative statics results for the regeneration process, all the others results are identical for the two instruments. These results confirm Proposition 1 according to which, savings and regeneration process could be substitutes.

\section{Corner solutions and extensions}

\subsection{Harvesting rules with binding constraints in the second period}

This paragraph deals explicitly with cases where the feasibility constraint for second-period harvesting rules binds. Such a constraint plays the role of a self-restraint mechanism or precautionary behavior which commits the NIPF not to harvest more than the worst (smallest) existing stock of timber that should arise at the beginning of period 2 (i.e. in cases where the realized forest growth 
is lowest).

In the savings model according to conditions (6), (7) and (8), the first order conditions for a (corner) solution with $s>0, x_{1}>0$ but $x_{2}=\underline{\theta} . g\left(Q-x_{1}\right)$ are given by the next three equations:

$$
\begin{array}{ll}
(D): & \pi_{1}^{\prime} \cdot u_{1}^{\prime}=m\left(1+\delta g^{\prime} E(\theta)\right)+\gamma \underline{\theta} g^{\prime} \\
(E) \quad: \quad \pi_{2}^{\prime} \cdot u_{2}^{\prime}-m=\frac{\gamma}{\delta} \\
(G) \quad: \quad u_{1}^{\prime}=\delta R u_{2}^{\prime}
\end{array}
$$

since $\mu=\sigma=0$ but $\gamma>0$ as the associated feasibility constraint binds (and condition (9) is still irrelevant).

More specifically, remark that condition (E) implies $\pi_{2}^{\prime} \cdot u_{2}^{\prime}>m$ at $x_{2}^{*}=\underline{\theta} \cdot g\left(k_{1}^{*}\right)$ meaning that the owner's satisfaction level (inter-temporal expected utility) increases at $x_{2}^{*}=\underline{\theta} \cdot g\left(k_{1}^{*}\right)$. As a consequence, when the (self-restraint) constraint on second-period harvesting is relaxed (or if we assume it totally vanishes), the owner will enjoy the opportunity to increase the second-period harvesting a little further, since this will make them better off. In a sense, condition (B) suggests that the smaller the value of the marginal utility of amenity services $(m)$, the easier or the more likely it is that this corner solution will occur.

In the silvicultural practice model, the corner solution with $q>0, x_{1}>0$ and $x_{2}=\underline{\theta} . g\left(Q-x_{1}\right)+q$ is associated with the next three conditions:

$$
\begin{aligned}
(K) \quad: \quad \pi_{1}^{\prime} \cdot u_{1}^{\prime}=m\left(1+\delta g^{\prime} E(\theta)\right)+\gamma \underline{\theta} \cdot g^{\prime} \\
(L) \quad: \quad \pi_{2}^{\prime} \cdot u_{2}^{\prime}=m+\frac{\gamma}{\delta} \\
(M) \quad: \quad c u_{1}^{\prime}=\delta m+\gamma
\end{aligned}
$$

where $\lambda>0$, since $\sigma=0, \lambda=0$, but $\gamma>0$ (and condition (8) is still irrelevant).

The next Proposition 7 and Corollary 8 summarize our findings. First, focusing on first-period harvesting rules, we have shown that:

Proposition 7 A) In the savings model, assuming that $R \frac{\pi_{1}^{\prime}}{\pi_{2}^{\prime}}>\frac{1}{\delta}$, then in a solution with $x_{2}=$ 
$\underline{\theta} . g\left(k_{1}\right)$, the period 1 harvesting rule satisfies:

$$
g^{\prime}\left(Q-x_{1}^{*}\right)=\left[\left(\frac{\pi_{2}^{\prime} u_{2}^{\prime}}{m}\right) \cdot R \frac{\pi_{1}^{\prime}}{\pi_{2}^{\prime}}-\frac{1}{\delta}\right] \times\left[\left(\left(\frac{\pi_{2}^{\prime} u_{2}^{\prime}}{m}\right)-1\right) \underline{\theta}+E(\theta)\right]^{-1}
$$

knowing that $s^{*}$ is given by condition $(G)$.

B) In the silvicultural practice model, assuming that $\frac{\pi_{1}^{\prime}}{c}>\frac{1}{\delta}$, then in a solution with $x_{2}=$ $\underline{\theta} . g\left(k_{1}\right)+q$, the period 1 harvesting rule satisfies:

$$
g^{\prime}\left(Q-x_{1}^{*}\right)=\left[\left(\frac{\pi_{2}^{\prime} u_{2}^{\prime}}{m}\right) \cdot \frac{\pi_{1}^{\prime}}{c}-\frac{1}{\delta}\right] \times\left[\left(\left(\frac{\pi_{2}^{\prime} u_{2}^{\prime}}{m}\right)-1\right) \underline{\theta}+E(\theta)\right]^{-1}
$$

knowing that $q^{*}$ is given by condition $(M)$.

Proof. A) In the savings model:

Let us substitute (E) in (D) to eliminate $\gamma>0$, then use $(G)$ and rearrange to obtain:

$$
\left(D^{\prime}\right) \quad: \quad g^{\prime}=\left[\left(\frac{\pi_{2}^{\prime} u_{2}^{\prime}}{m}\right) \cdot R \frac{\pi_{1}^{\prime}}{\pi_{2}^{\prime}}-\frac{1}{\delta}\right] \times\left[\left(\left(\frac{\pi_{2}^{\prime} u_{2}^{\prime}}{m}\right)-1\right) \underline{\theta}+E(\theta)\right]^{-1}
$$

Note that according to (E) we obtain $\frac{\pi_{2}^{\prime} u_{2}^{\prime}}{m}>1$, and thus $R \frac{\pi_{1}^{\prime}}{\pi_{2}^{\prime}}>\frac{1}{\delta}$ is still a sufficient (stronger than needed) condition for having a $x_{1}>0$ satisfying condition (D'). Finally, solving (D')-(G) gives the first-period harvesting rule and the optimal level of saving, while the value for $\gamma$ results from condition (E).

B) In the silvicultural model:

Using (L) and (M) we obtain $u_{1}^{\prime}=\delta \frac{\pi_{2}^{\prime}}{c} \cdot u_{2}^{\prime}$, then substituting in (K) yields:

$$
\left(K^{\prime}\right): g^{\prime}=\left[\left(\frac{\pi_{2}^{\prime} u_{2}^{\prime}}{m}\right) \cdot \frac{\pi_{1}^{\prime}}{c}-\frac{1}{\delta}\right] \times\left[\left(\left(\frac{\pi_{2}^{\prime} u_{2}^{\prime}}{m}\right)-1\right) \underline{\theta}+E(\theta)\right]^{-1}
$$

Once more, given that according to $(\mathrm{L})$ we have $\frac{\pi_{2}^{\prime} u_{2}^{\prime}}{m}>1$, then $\frac{\pi_{1}^{\prime}}{c}>\frac{1}{\delta}$ is still a sufficient (stronger than needed) condition to have $x_{1}>0$ satisfying (K'). Solving now simultaneously (K')(L)-(M) gives the optimal harvesting rule for the first period, the optimal silvicultural practice and $\gamma$ 
Moreover, we obtain the next result:

Corollary 8 A) In both the savings and silvicultural practice models, the first-period harvesting amount is larger when the feasibility constraint on second-period harvesting binds than when it does not.

B) In the savings model, the savings accumulated are larger when the feasibility constraint on second-period harvesting binds than when it does not.

C) In the physical model, the level of physical practices undertaken is larger when the feasibility constraint on second-period harvesting binds than when it does not.

Proof. A) Let us give the explicit argument for the savings model. It amounts to comparing the RHS in (14) and (10). Under the condition $R \frac{\pi_{1}^{\prime}}{\pi_{2}^{\prime}}>\frac{1}{\delta}$, it can be verified that the next inequality:

$$
\frac{1}{E(\theta)} \cdot\left(R \frac{\pi_{1}^{\prime}}{\pi_{2}^{\prime}}-\frac{1}{\delta}\right)<\left[\left(\frac{\pi_{2}^{\prime} u_{2}^{\prime}}{m}\right) \cdot R \frac{\pi_{1}^{\prime}}{\pi_{2}^{\prime}}-\frac{1}{\delta}\right] \times\left[\left(\left(\frac{\pi_{2}^{\prime} u_{2}^{\prime}}{m}\right)-1\right) \underline{\theta}+E(\theta)\right]^{-1}
$$

is equivalent to:

$$
-\frac{\theta}{\delta}<(E(\theta)-\underline{\theta}) R \frac{\pi_{1}^{\prime}}{\pi_{2}^{\prime}}
$$

once the condition has been simplified in order to remove the term $\frac{\pi_{2}^{\prime} u_{2}^{\prime}}{m}-1>0$ from both sides. But this last inequality is still true since $E(\theta)>\underline{\theta}$. As a result, given that the LHS in both (10) and (14) is an increasing function of $x_{1}$, the equilibrium value for $x_{1}$ satisfying (10) is smaller than the one satisfying (14).

B) Simply, since mixing (E) and (G) yields $u_{1}^{\prime}=\frac{\delta R}{\pi_{2}^{\prime}}\left(m+\frac{\gamma}{\delta}\right)>\frac{\delta R}{\pi_{2}^{\prime}} m$; thus comparing with (C'), the value of $s$ which satisfies $(\mathrm{G})$ is larger than the one satisfying $\left(\mathrm{C}^{\prime}\right)$.

C) A similar argument may be used for $q$; this is left to the reader.

Corollary 8 implies that, should the NIPF impose a self-restraint constraint on his second-period harvesting rule of his own choice, then this leads him to compensate with a higher level of cutting in the first period. At the same time, the available instrument (savings or silvicultural practices) is increased to a higher level since it is used to transfer the additional harvesting income to the second period, in order to allow for the smoothing of consumption. This shows that the choice of a harvesting strategy and hedging strategy is designed to reach the best smoothing of consumption 
flows between both periods.

\subsection{Concave amenity services}

In this paragraph, we assess the impact of the shape of the utility derived from amenity services, assuming a concave utility function. Comparing our results to the previous case with a constant marginal utility allows us to enhance the role of different NIPF owner preferences. In order to remove redundancies, we will focus only on the interior solution in the savings model, but the same analysis may be performed in the silvicultural practice model, and/or when the feasibility constraint binds.

To begin with, note that the results displayed in Proposition 6 are true whether or not the future value of amenities is known with certainty: given the (positive) terminal value corresponding to the utility of amenity services, the forest owner voluntarily limits harvesting in both periods. But as $m \rightarrow 0$, the owner behaves more and more closely to a profit-maximizing individual. In contrast, considering the case where the forest owner has a concave utility for amenity services means that the forest owner is averse to the uncertainty associated with the value of future stands, since she/he does not like spreading the shock $\theta$ in $[\underline{\theta}, \bar{\theta}]$.

Proposition 9 In the savings model, all else held equal, the harvesting rules for both periods (in a pure interior solution with $\left.x_{2}<\underline{\theta} . g\left(k_{1}\right)\right)$ may lead to a higher level of cutting with a concave utility for amenity services, as compared to the linear case. But the opposite result may also hold.

Proof. Assume that $v$ the utility function for amenity services is concave. Relaxing the assumption of a constant marginal utility for amenity services yields the following first order conditions in the savings model:

$$
\begin{array}{ll}
(N) \quad: \quad \pi_{1}^{\prime} \cdot u_{1}^{\prime}=v_{1}^{\prime}+\delta g^{\prime} \cdot E\left(\theta \cdot v_{2}^{\prime}\right) \\
(O) \quad: \quad \pi_{2}^{\prime} \cdot u_{2}^{\prime}=E\left(v_{2}^{\prime}\right) \\
(P) \quad: \quad u_{1}^{\prime}=\delta R u_{2}^{\prime}
\end{array}
$$

which substitutes with the system $(\mathrm{A})-(\mathrm{B})-(\mathrm{C})$. Note that using $(\mathrm{O})$ and $(\mathrm{P})$ in $(\mathrm{N})$ yields: 


$$
\begin{aligned}
& R \frac{\pi_{1}^{\prime}}{\pi_{2}^{\prime}}-\frac{1}{\delta} \frac{v_{1}^{\prime}}{E v_{2}^{\prime}}=g^{\prime} \cdot \frac{E\left(\theta \cdot v_{2}^{\prime}\right)}{E v_{2}^{\prime}}>0 \\
& \Downarrow \\
& R \frac{\pi_{1}^{\prime}}{\pi_{2}^{\prime}}-\frac{1}{\delta} \frac{v_{1}^{\prime}}{E v_{2}^{\prime}}=g^{\prime} \cdot\left[E(\theta)+\frac{\operatorname{cov}\left(\theta, v_{2}^{\prime}\right)}{E\left(v_{2}^{\prime}\right)}\right]
\end{aligned}
$$

where $\operatorname{cov}\left(\theta, v_{2}^{\prime}\right)<0$. But the concavity of the amenity services modifies the psychological costs (or opportunity costs) of harvesting as compared to the linear case in several ways.

On the one hand, it reduces the owner's individual assessment of the risk-adjusted marginal product of the forest growth process since $g^{\prime} \cdot\left[E(\theta)+\frac{\operatorname{cov}\left(\theta, v_{2}^{\prime}\right)}{E\left(v_{2}^{\prime}\right)}\right]<g^{\prime} \cdot E(\theta)$ : given the concavity of $v$, the dispersion of shock $\theta$ is seen as a cost (the price of risk) which affects her/his perception of the natural productivity for the growth process; as a result, this first effect has a negative impact on the period 1 harvesting decision.

On the other hand, a non-linear utility for amenity services modifies the tradeoff between amenity services in period 1 and those of period 2 , through the ratio $\frac{E\left(v_{2}^{\prime}\right)}{v_{1}^{\prime}} \gtrless 1$. However, these effects are ambiguous. Thus, the specific result depends in particular on the characteristics of the risk, and on the properties of function $v$.

At the same time, according to condition $(\mathrm{O})$, the result for $x_{2}$ depends on whether $m \lessgtr E\left(v_{2}^{\prime}\right)$. Once more, this requires more restriction on function $v$ and on the probability distribution of $\sigma$.

\subsection{Delayed versus early resolution of uncertainty}

Let us assume once more that $v^{\prime}=m$, but introduce another representation of uncertainty, named early resolution of uncertainty, which is associated with the random variable $\sigma$, the value of which is resolved at the beginning of the growth process, as illustrated in Figure 2. 
Figure 2: Early resolution of uncertainty

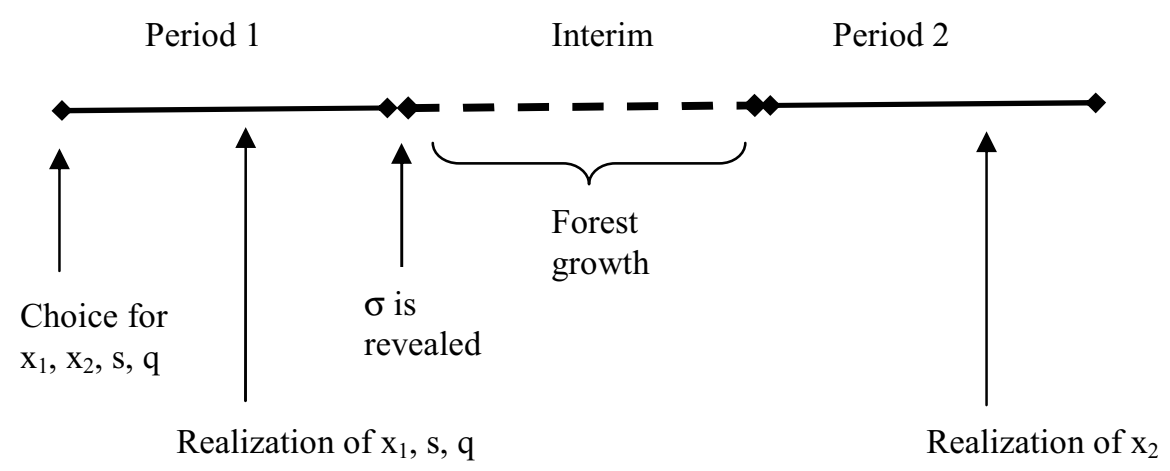

This means that $\sigma$ is now revealed and observed by the forest owner at the end of period 1 (at the beginning of the interim period), and thus before the realization of the second-period harvesting decision, such that the value of the stand at the end of the growth process and before that harvesting takes place is $g\left(\sigma k_{1}\right)$. The possible realizations for $\sigma$ are described according to a probability distribution which is assumed to be known by the forest owner at the beginning of period 1 , and represented by a cumulative function denoted $L(\sigma)$ defined on $[\underline{\sigma}, \bar{\sigma}] \subset[0,1]$ and with a density $l(\sigma)>0$ everywhere. Remark once more that we may choose $\underline{\sigma}$ as close as possible to 0 , which may be seen as the realization of a catastrophic event implying that the forest is fully destroyed. In this case, any harvesting decision $x_{2}>0$ set in period 1 appears not to be feasible. In contrast, as $\sigma \rightarrow 1$, the event corresponds to the best outcome for the NIPF owner, when no natural risk damages the forest property. Note that we develop the analysis explicitly in the savings model; however, it can be verified that the same kind of results are obtained in the silvicultural practice model.

The optimal first-period harvesting rule for the financial practice model is defined as follows:

i) If $x_{2}<\underline{\theta} . g\left(k_{1}\right)$, then the optimal first-period harvesting decision satisfies:

$$
R \frac{\pi_{1}^{\prime}}{\pi_{2}^{\prime}}-\frac{1}{\delta}=E\left(\sigma \cdot g^{\prime}\left(\sigma \cdot k_{1}^{*}\right)\right)
$$

ii) if $x_{2}=\underline{\theta} \cdot g\left(k_{1}\right)$, then the optimal first-period harvesting rule satisfies:

$$
\left(\frac{\pi_{2}^{\prime} u_{2}^{\prime}}{m}\right) \cdot R \frac{\pi_{1}^{\prime}}{\pi_{2}^{\prime}}-\frac{1}{\delta}=\left(\left(\frac{\pi_{2}^{\prime} u_{2}^{\prime}}{m}\right)-1\right) g^{\prime}\left(\underline{\sigma} \cdot k_{1}^{*}\right) \cdot \underline{\sigma}+E\left(\sigma \cdot g^{\prime}\left(\sigma \cdot k_{1}^{*}\right)\right)
$$


while the first order conditions for the optimal second-period harvesting and savings decisions are identical. We prove the next result:

Proposition 10 In the savings model, whether $x_{2}<\underline{\theta} . g\left(k_{1}\right)$ or $x_{2}=\underline{\theta} . g\left(k_{1}\right)$ holds, then, all else held equal, the period 1 harvesting rule leads to a higher level of cutting with the delayed resolution of uncertainty than with the early resolution of uncertainty.

Proof. The result holds whatever the model, since for any two random variables $X, Z$, we have by definition $E(X . Z)=E(X) \cdot E(Z)+\operatorname{cov}(X, Z)$. Thus, let us consider for example the model with savings, and its solution when the feasibility constraint does not bind. Assume more particularly that the probability distribution of both $\theta$ and $\sigma$ have the same mean $E(\theta)=E(\sigma)$. Using the RHS of condition (16), we may write: $E\left(\sigma \cdot g^{\prime}\left(k_{1}^{*}\right)\right)=E(\sigma) \cdot E\left(g^{\prime}\left(\sigma \cdot k_{1}^{*}\right)\right)+\operatorname{cov}\left(\sigma, g^{\prime}\left(\sigma \cdot k_{1}^{*}\right)\right)>0$. Given the concavity of $g$, as $\sigma$ increases then $g^{\prime}\left(\sigma . k_{1}^{*}\right)$ decreases, implying that $\operatorname{cov}\left(\sigma, g^{\prime}\left(\sigma . k_{1}^{*}\right)\right)<0$. As a result:

$$
\begin{aligned}
R \frac{\pi_{1}^{\prime}}{\pi_{2}^{\prime}}-\frac{1}{\delta} & =E\left(\sigma \cdot g^{\prime}\left(\sigma \cdot k_{1}^{*}\right)\right) \\
& =E(\sigma) \cdot E\left(g^{\prime}\left(\sigma \cdot k_{1}^{*}\right)\right)+\operatorname{cov}\left(\sigma, g^{\prime}\left(\sigma \cdot k_{1}^{*}\right)\right) \\
& <E(\sigma) \cdot E\left(g^{\prime}\left(\sigma \cdot k_{1}^{*}\right)\right)
\end{aligned}
$$

and under the assumption that $E(\theta)=E(\sigma)$, then the LHS in (10) is larger than the one in (16), yielding a larger amount for period 1 harvesting with delayed resolution of uncertainty.

Coming back to the previous analysis of the amenity effect, the intuition of the result is that the psychological costs associated with the early resolution of uncertainty are larger with delayed resolution of uncertainty than with an early one.

\section{Conclusion}

Some empirical studies suggest that NIPF owners produce timber income and non-timber benefits jointly. Utility-maximization recognizes that forest owners may gain non-pecuniary benefits such as aesthetics, recreation and wildlife habitat from the forest stands on their land, in addition to the value of timber. In many cases, landowners still appear to have an interest in producing both timber income and forest amenities jointly. The substitution between harvesting and non-timber preferences has been of particular interest. In this article, we develop a dynamic theoretical model 
to analyze the NIPF owner's behavior in risky forest management. We study two hedging activities that the forest owner can undertake to protect the forest against natural hazards: the savings and the regeneration processes. In this work, there are several contributions. First, we extend the two-period biomass harvesting model by integrating the hedging strategies. In this framework, we demonstrate that under some assumptions, the accumulation of savings and the regeneration process may be seen as perfectly substitutable for forest owners. Second, we analyze the impact of amenity services on optimal harvesting decisions. Third, we develop the comparative statics of harvesting strategies by studying the effect of each parameter and uncertainty on the optimal decisions. For example, we show that, when the expected risk increases, the owner reduces first-period harvesting and the use of hedging strategies (whatever the measure) while she/he increases second-period harvesting in the savings model and has a null effect in the silvicultural practice one.

Several extensions are worth discussing for this research. First, our assumption of a constant marginal utility for amenity services could be seen as a limit of this paper, but this assumption makes the analysis much more transparent. We can easily generalize our analysis assuming that the marginal utility is not constant, but we know that we can expect to obtain ambiguous results of comparative statics. This extension is analyzed in the paper by considering a concave marginal utility for amenities.

Our results cannot be challenged without introducing some frictions or imperfections in the model. For example, the basic two-period model we use implies that both financial (savings) and silvicultural (regeneration process) practice are held for the same (short-term) horizon. However, due to imperfections in the financial markets on the one hand (asymmetrical information, borrowing constraints, different interest rates for lenders and borrowers), and on the other hand, given the existence of a natural delay between the plantation of the trees and their harvesting, the horizon of decisions in financial markets may be shorter than for decisions connected to the regeneration process. Moreover, the production process in forestry may be more or less lengthy, depending on the choice of tree species.

In the same way, another extension consists in the possibility for the forest owners of learning the state of the world (gathering information on the weather, and thus on $\theta$ ). We can expect that when information has a positive value, it will be used by forest owners in order to plan both their harvesting decisions and their risk management ones. These important extensions are left for future research. 


\section{References}

[1] T. Birch, Private forest-land owners of the northern United States, USDA Forest Services, Bulletin NE-136, 1994.

[2] B. Butler, E. Leatherberry, National woodland owner survey: 2004 preliminary results, USDA Forest Service. http://www.fs.fed.us/woodlandowners/, 2005.

[3] M. Schelhaas, G. Nabuurs, A. Schuck, Natural disturbances in the european forests in the 19th and 20th centuries, Global Change Biology 9 (2003) 1620-1633.

[4] M. Brunette, S. Couture, Public compensation for windstorm damage reduces incentives for risk management investments, Forest Policy and Economics 10 (2008) 491-499.

[5] C. of the European Communities (CEC), Communication from the Commission to the Council and the European Parliament on an EU Forest Action Plan., Available at: http : //ec.europa.eu/agriculture/fore/action_plan/com_en.pdf., 2006.

[6] Food, A. O. (FAO), State of the World's Forest, FAO, Rome, 146p., 2007.

[7] L. Alvarez, E. Koskela, On forest rotation under interest rate variability, International Tax and Public Finance 10 (2003) 489-503.

[8] L. Alvarez, E. Koskela, Wicksellian theory of forest rotation under interest rate variability, Journal of Economic Dynamics and Control 29 (2005) 529-545.

[9] L. Alvarez, E. Koskela, Does risk aversion accelerate optimal forest rotation under uncertainty?, Journal of Forest Economics 12 (2006) 171-184.

[10] P. Lohmander, Optimal harvest policy under the influence of imperfections and uncertainty, swedish University of Agriculture Science, Working Paper 22. Umeå, Sweden. 72p. (1983).

[11] E. Koskela, Forest taxation and timber supply under price uncertainty: Perfect capital markets, Forest Science 35 (1) (1989) 137-159.

[12] J. Kuuluvainen, Nonindustrial private timber supply and credit rationing: Microeconomic foundations with empirical evidence from the Finnish case, Swedish University of Agriculture Sciences, Report 85. Umeå, Sweden., 1989.

[13] V. Ovaskainen, Forest taxation, timber supply and economic efficiency, Acta Forestalia Fennica 233, 88p., 1992. 
[14] C. Binkley, Economic analysis of the allowable cut effect, Forest Science 24 (6) (1980) 633-642.

[15] P. Johansson, K. Löfgren, Six different results on the properties of the timber supply function, Swedish University of Agricultural Sciences, Report 39. Umeå, Sweden. 14 p., 1982.

[16] J. Kuuluvainen, Virtual price approach to short-term timber supply under credit rationning, Journal of Environmental Economics and Management 19 (1990) 109-126.

[17] J. Kuuluvainen, J. Salo, Timber supply and life cycle harvest of non-industrial private forest owners, an empirical analysis of the finnish case, Forest Science 37 (1991) 1011-1029.

[18] E. Koskela, M. Ollikainen, Optimal design of forest taxation with multiple-use characteristics of forest stands, Environmental and Resource Economics 10 (1997) 41-62.

[19] E. Koskela, M. Ollikainen, Timber supply, amenity values and biological risk, Journal of Forest Economics 5 (2) (1999) 285-304.

[20] W. Reed, Protecting a forest against fire: Optimal protection patterns and harvest policies, Natural Resource Modeling 21 (1) (1987) 23-53.

[21] G. Amacher, A. Malik, R. Haight, Not getting burned: the importance of fire prevention in forest management, Land Economics 81 (2) (2005) 284-302.

[22] W. Max, D. Lehman, A behavioral model of timber supply, Journal of Environmental Economics and Management 15 (1988) 71-86.

[23] V. Ovaskainen, H. Hänninen, J. Mikkola, E. Lehtonen, Cost-sharing and private timber stand improvements: a two-step estimation approach, Forest Science 52 (1) (2006) 44-54. 


\section{A Second order conditions}

Consider the savings model. The matrix of the second order derivatives is:

$$
\begin{aligned}
\Delta & =\left|\begin{array}{ccc}
V_{x_{1} x_{1}} & V_{x_{1} x_{2}} & V_{x_{1} s} \\
V_{x_{2} x_{1 s}} & V_{x_{2} x_{2 s}} & V_{x_{2} s} \\
V_{s x_{1}} & \delta V_{s x_{2}} & V_{s s}
\end{array}\right|=\left|\begin{array}{ccc}
V_{x_{1} x_{1}} & 0 & V_{x_{1} s} \\
0 & V_{x_{2} x_{2}} & V_{x_{2} s} \\
V_{s x_{1}} & \delta V_{s x_{2}} & V_{s s}
\end{array}\right| \\
= & \left|\begin{array}{ccc}
\left(\pi_{1}^{\prime}\right)^{2} u^{\prime \prime}\left(c_{1}\right)+m \delta E(\theta) g^{\prime \prime}\left(k_{1}\right) & 0 & -\pi_{1}^{\prime} u^{\prime \prime}\left(c_{1}\right) \\
0 & \left(\pi_{2}^{\prime}\right)^{2} u^{\prime \prime}\left(c_{2}\right) & R \pi_{2}^{\prime} u^{\prime \prime}\left(c_{2}\right) \\
-\pi_{1}^{\prime} u^{\prime \prime}\left(c_{1}\right) & \delta R \pi_{2}^{\prime} u^{\prime \prime}\left(c_{2}\right) & u^{\prime \prime}\left(c_{1}\right)+\delta R^{2} u^{\prime \prime}\left(c_{2}\right)
\end{array}\right|
\end{aligned}
$$

The second order conditions are verified if the minors alternate in signs:

$$
\begin{array}{r}
V_{x_{1} x_{1}}<0 \\
\left|\begin{array}{ll}
V_{x_{1} x_{1}} & V_{x_{1} x_{2}} \\
V_{x_{2} x_{1}} & V_{x_{2} x_{2}}
\end{array}\right|>0 \\
\left|\begin{array}{ccc}
V_{x_{1} x_{1}} & V_{x_{1} x_{2}} & V_{x_{1} s} \\
V_{x_{2} x_{1}} & V_{x_{2} x_{2}} & V_{x_{2} s} \\
V_{s x_{1}} & \delta V_{s x_{2}} & V_{s s}
\end{array}\right|<0
\end{array}
$$

It is easy to verify that the restrictions on $u$, and $g\left(u^{\prime \prime}<0, g^{\prime \prime}<0\right)$ are sufficient.

\section{B Comparative statics results}

Consider the savings model with an interior solution. Given that $\Delta<0$ (Appendix A), we have:

1/ A change in period 1 exogenous income: $Y_{1}$

$$
\frac{d x_{1}}{d Y_{1}}=\frac{1}{\Delta}\left|\begin{array}{ccc}
-\pi_{1}^{\prime} \cdot u_{1}^{\prime \prime} & 0 & V_{x_{1} s} \\
0 & V_{x_{2} x_{2}} & V_{x_{2} s} \\
u_{1}^{\prime \prime} & \delta V_{s x_{2}} & V_{s s}
\end{array}\right|<0
$$




$$
\begin{aligned}
& \frac{d x_{2}}{d Y_{1}}=\frac{1}{\Delta}\left|\begin{array}{ccc}
V_{x_{1} x_{1}} & -\pi_{1}^{\prime} \cdot u_{1}^{\prime \prime} & V_{x_{1} s} \\
0 & 0 & V_{x_{2} s} \\
V_{s x_{1}} & u_{1}^{\prime \prime} & V_{s s}
\end{array}\right|<0 \\
& \frac{d s}{d Y_{1}}=\frac{1}{\Delta}\left|\begin{array}{ccc}
V_{x_{1} x_{1}} & 0 & -\pi_{1}^{\prime} \cdot u_{1}^{\prime \prime} \\
0 & V_{x_{2} x_{2}} & 0 \\
V_{s x_{1}} & \delta V_{s x_{2}} & u_{1}^{\prime \prime}
\end{array}\right|>0
\end{aligned}
$$

$2 /$ A change in period 2 exogenous income: $Y_{2}$

$$
\begin{aligned}
& \frac{d x_{1}}{d Y_{2}}=\frac{1}{\Delta}\left|\begin{array}{ccc}
0 & 0 & V_{x_{1} s} \\
-\pi_{2}^{\prime} \cdot u_{2}^{\prime \prime} & V_{x_{2} x_{2}} & V_{x_{2} s} \\
-\delta R u_{2}^{\prime \prime} & \delta V_{s x_{2}} & V_{s s}
\end{array}\right|<0 \\
& \frac{d x_{2}}{d Y_{2}}=\frac{1}{\Delta}\left|\begin{array}{ccc}
V_{x_{1} x_{1 s}} & 0 & V_{x_{1} s} \\
0 & -\pi_{2}^{\prime} \cdot u_{2}^{\prime \prime} & V_{x_{2} s} \\
V_{s x_{1}} & -\delta R u_{2}^{\prime \prime} & V_{s s}
\end{array}\right|<0 \\
& \frac{d s}{d Y_{2}}=\frac{1}{\Delta}\left|\begin{array}{ccc}
V_{x_{1} x_{1 s}} & 0 & 0 \\
0 & V_{x_{2} x_{2}} & -\pi_{2}^{\prime} \cdot u_{2}^{\prime \prime} \\
V_{s x_{1}} & \delta V_{s x_{2}} & -\delta R u_{2}^{\prime \prime}
\end{array}\right|<0
\end{aligned}
$$

3/ A change in initial forest stock: $Q$

$$
\begin{aligned}
& \frac{d x_{1}}{d Q}=\frac{1}{\Delta}\left|\begin{array}{ccc}
\delta m g^{\prime \prime}\left(k_{1}\right) E(\theta) & 0 & V_{x_{1} s} \\
0 & V_{x_{2} x_{2}} & V_{x_{2} s} \\
0 & \delta V_{s x_{2}} & V_{s s}
\end{array}\right|>0 \\
& \frac{d x_{2}}{d Q}=\frac{1}{\Delta}\left|\begin{array}{ccc}
V_{x_{1} x_{1 s}} & \delta m g^{\prime \prime}\left(k_{1}\right) E(\theta) & V_{x_{1} s} \\
0 & 0 & V_{x_{2} s} \\
V_{s x_{1}} & 0 & V_{s s}
\end{array}\right|<0
\end{aligned}
$$




$$
\frac{d s}{d Q}=\frac{1}{\Delta}\left|\begin{array}{ccc}
V_{x_{1} x_{1 s}} & 0 & \delta m g^{\prime \prime}\left(k_{1}\right) E(\theta) \\
0 & V_{x_{2} x_{2}} & 0 \\
V_{s x_{1}} & \delta V_{s x_{2}} & 0
\end{array}\right|>0
$$

4/ A change in period 1 harvesting price: $p_{1}$

$$
\begin{aligned}
\frac{d x_{1}}{d p_{1}} & =\frac{1}{\Delta}\left|\begin{array}{ccc}
-u_{1}^{\prime}-\pi_{1}^{\prime} \cdot u_{1}^{\prime \prime} \cdot x_{1} & 0 & V_{x_{1} s} \\
0 & V_{x_{2} x_{2}} & V_{x_{2} s} \\
u_{1}^{\prime \prime} \cdot x_{1} & \delta V_{s x_{2}} & V_{s s}
\end{array}\right| \\
& =\frac{-\delta u_{1}^{\prime}}{\Delta}\left|\begin{array}{cc}
V_{x_{2} x_{2}} & V_{x_{2} s} \\
V_{s x_{2}} & V_{s s}
\end{array}\right|+\frac{d x_{1}}{d Y_{1}} \cdot x_{1}
\end{aligned}
$$

The sign of $\frac{d x_{1}}{d p_{1}}$ is ambiguous because we have a negative income effect associated with a positive substitution effect. Nevertheless, if we turn to the partial risk aversion coefficient, we find that $x_{1}$ increases when $p_{1}$ rises.

Indeed, the last expression can be rewritten as follows:

$$
\frac{d x_{1}}{d p_{1}}=\frac{1}{\Delta}\left\{\pi^{\prime \prime}\left(x_{2}\right) u^{\prime}\left(c_{2}\right) \delta R^{2} u^{\prime \prime}\left(c_{2}\right)\left[-u^{\prime}\left(c_{1}\right)-\pi^{\prime}\left(x_{1}\right) u^{\prime \prime}\left(c_{1}\right) x_{1}\right]-u^{\prime}\left(c_{1}\right) u^{\prime \prime}\left(c_{1}\right) V_{x_{2} x_{2}}\right\}
$$

The term $\left[-u^{\prime}\left(c_{1}\right)-\pi^{\prime}\left(x_{1}\right) u^{\prime \prime}\left(c_{1}\right) x_{1}\right]$ is ambiguous and can be rewritten as follows:

$$
u^{\prime}\left(c_{1}\right)\left[-1+\left(-\frac{u^{\prime \prime}\left(c_{1}\right)}{u^{\prime}\left(c_{1}\right)} \pi^{\prime}\left(x_{1}\right) x_{1}\right)\right]
$$

This last expression allows us to observe a partial risk aversion coefficient: $-\frac{u^{\prime \prime}\left(c_{1}\right)}{u^{\prime}\left(c_{1}\right)} \pi^{\prime}\left(x_{1}\right) x_{1}$. If this coefficient is less than 1 , then $\frac{d x_{1}}{d p_{1}}>0$. The substitution effect is stronger than the income effect. 


$$
\begin{aligned}
\frac{d x_{2}}{d p_{1}} & =\frac{1}{\Delta}\left|\begin{array}{ccc}
V_{x_{1} x_{1}} & -u_{1}^{\prime}-\pi_{1}^{\prime} \cdot u_{1}^{\prime \prime} \cdot x_{1} & V_{x_{1} s} \\
0 & 0 & V_{x_{2} s} \\
V_{s x_{1}} & u_{1}^{\prime \prime} \cdot x_{1} & V_{s s}
\end{array}\right| \\
& =\frac{-u_{1}^{\prime}}{\Delta} V_{x_{2} s} \cdot V_{s x_{1}}+\frac{d x_{2}}{d Y_{1}} \cdot x_{1}<0 \\
\frac{d s}{d p_{1}} & =\frac{1}{\Delta}\left|\begin{array}{ccc}
V_{x_{1} x_{1}} & 0 & -u_{1}^{\prime}-\pi_{1}^{\prime} \cdot u_{1}^{\prime \prime} \cdot x_{1} \\
0 & V_{x_{2} x_{2}} & 0 \\
V_{s x_{1}} & \delta V_{s x_{2}} & u_{1}^{\prime \prime} \cdot x_{1}
\end{array}\right| \\
& =\frac{-u_{1}^{\prime}}{\Delta} V_{x_{2} x_{2}} \cdot V_{s x_{1}}+\frac{d s}{d Y_{1}} \cdot x_{1}>0
\end{aligned}
$$

5/ A change in period 2 harvesting price: $p_{2}$

$$
\begin{aligned}
& \frac{d x_{1}}{d p_{2}}=\frac{1}{\Delta}\left|\begin{array}{ccc}
0 & 0 & V_{x_{1} s} \\
-u_{2}^{\prime}-\pi_{2}^{\prime} \cdot u_{2}^{\prime \prime} \cdot x_{2} & V_{x_{2} x_{2}} & V_{x_{2} s} \\
\delta R u_{2}^{\prime \prime} \cdot x_{2} & \delta V_{s x_{2}} & V_{s s}
\end{array}\right| \\
& =\frac{-u_{2}^{\prime}}{\Delta} V_{x_{1} s} \cdot V_{x_{2} s}+\frac{d x_{1}}{d Y_{2}} \cdot x_{2}<0 \\
& \frac{d x_{2}}{d p_{2}}=\frac{1}{\Delta}\left|\begin{array}{ccc}
V_{x_{1} x_{1}} & 0 & V_{x_{1} s} \\
0 & -u_{2}^{\prime}-\pi_{2}^{\prime} \cdot u_{2}^{\prime \prime} \cdot x_{2} & V_{x_{2} s} \\
V_{s x_{1}} & \delta R u_{2}^{\prime \prime} \cdot x_{2} & V_{s s}
\end{array}\right| \\
& =\frac{-u_{2}^{\prime}}{\Delta}\left|\begin{array}{cc}
V_{x_{1} x_{1}} & V_{x_{1} s} \\
V_{s x_{1}} & V_{s s}
\end{array}\right|+\frac{d x_{2}}{d Y_{2}} \cdot x_{2}
\end{aligned}
$$

The sign of $\frac{d x_{2}}{d p_{2}}$ is ambiguous because we have a negative income effect associated with a positive substitution effect. Nevertheless, if we turn to the partial risk aversion coefficient, we find that $x_{2}$ increases when $p_{2}$ rises.

Indeed, the last expression can be rewritten as follows:

$$
\frac{d x_{2}}{d p_{2}}=\frac{1}{\Delta}\left\{u^{\prime \prime}\left(c_{1}\right)\left[\pi^{\prime \prime}\left(x_{1}\right) u^{\prime}\left(c_{1}\right)+\delta m \theta g^{\prime \prime}\left(k_{1}\right)\right]\left[-u^{\prime}\left(c_{2}\right)-\pi^{\prime}\left(x_{2}\right) u^{\prime \prime}\left(c_{2}\right) x_{2}\right]\right\}
$$


The term $\left[-u^{\prime}\left(c_{2}\right)-\pi^{\prime}\left(x_{2}\right) u^{\prime \prime}\left(c_{2}\right) x_{2}\right]$ is ambiguous and can be rewritten as follows:

$$
u^{\prime}\left(c_{2}\right)\left[-1+\left(-\frac{u^{\prime \prime}\left(c_{2}\right)}{u^{\prime}\left(c_{2}\right)} \pi^{\prime}\left(x_{2}\right) x_{2}\right)\right]
$$

This last expression allows us to observe a partial risk aversion coefficient: $-\frac{u^{\prime \prime}\left(c_{2}\right)}{u^{\prime}\left(c_{2}\right)} \pi^{\prime}\left(x_{2}\right) x_{2}$. If this coefficient is less than to 1 , then $\frac{d x_{2}}{d p_{2}}>0$. The substitution effect is stronger than the income effect.

$$
\begin{aligned}
\frac{d s}{d p_{2}} & =\frac{1}{\Delta}\left|\begin{array}{ccc}
V_{x_{1} x_{1}} & 0 & 0 \\
0 & V_{x_{2} x_{2}} & -u_{2}^{\prime}-\pi_{2}^{\prime} \cdot u_{2}^{\prime \prime} \cdot x_{2} \\
V_{s x_{1}} & \delta V_{s x_{2}} & \delta R u_{2}^{\prime \prime} \cdot x_{2}
\end{array}\right| \\
& =\frac{u_{2}^{\prime}}{\Delta} V_{x_{1} x_{1}} \cdot \delta V_{s x_{2}}+\frac{d s}{d Y_{2}} \cdot x_{2}<0
\end{aligned}
$$

5/ A change in rate of return: $R$

$$
\begin{aligned}
\frac{d x_{1}}{d R} & =\frac{1}{\Delta}\left|\begin{array}{ccc}
0 & 0 & V_{x_{1} s} \\
-\pi_{2}^{\prime} \cdot u_{2}^{\prime \prime} \cdot s & V_{x_{2} x_{2}} & V_{x_{2} s} \\
-\delta R u_{2}^{\prime \prime} \cdot s-\delta u_{2}^{\prime} & \delta V_{s x_{2}} & V_{s s}
\end{array}\right| \\
& =\frac{\delta u_{2}^{\prime}}{\Delta} V_{x_{1} s} \cdot V_{x_{2} x_{2}}+\frac{d x_{1}}{d Y_{2}} \cdot s
\end{aligned}
$$

The sign of $\frac{d x_{1}}{d R}$ is ambiguous because we have a negative income effect associated with another effect which is positive. Nevertheless, if we turn to the partial risk aversion coefficient, we find that $x_{1}$ increases when $R$ rises.

Indeed, the last expression can be rewritten as follows:

$$
\frac{d x_{1}}{d R}=\frac{1}{\Delta}\left\{\pi^{\prime \prime}\left(x_{2}\right) u^{\prime}\left(c_{2}\right) \pi^{\prime}\left(x_{1}\right) u^{\prime \prime}\left(c_{1}\right)\left[-\delta u^{\prime}\left(c_{2}\right)-\delta R u^{\prime \prime}\left(c_{2}\right) s\right]-\delta u^{\prime}\left(c_{2}\right) \pi^{\prime}\left(x_{1}\right) u^{\prime \prime}\left(c_{1}\right)\left(\pi^{\prime}\left(x_{2}\right)\right)^{2} u^{\prime \prime}\left(c_{2}\right)\right\}
$$

The term $\left[-\delta u^{\prime}\left(c_{2}\right)-\delta R u^{\prime \prime}\left(c_{2}\right) s\right]$ is ambiguous and can be rewritten as follows:

$$
\delta u^{\prime}\left(c_{2}\right)\left[-1+\left(-\frac{u^{\prime \prime}\left(c_{2}\right)}{u^{\prime}\left(c_{2}\right)} R s\right)\right]
$$

This last expression allows us to observe a partial risk aversion coefficient: $-\frac{u^{\prime \prime}\left(c_{2}\right)}{u^{\prime}\left(c_{2}\right)} R s$. If this coefficient is less than 1 , then $\frac{d x_{1}}{d R}>0$. The positive effect is stronger than the income effect. 


$$
\begin{aligned}
\frac{d x_{2}}{d R} & =\frac{1}{\Delta}\left|\begin{array}{ccc}
V_{x_{1} x_{1}} & 0 & V_{x_{1} s} \\
0 & -\pi_{2}^{\prime} \cdot u_{2}^{\prime \prime} . s & V_{x_{2} s} \\
V_{s x_{1}} & -\delta R u_{2}^{\prime \prime} \cdot s-\delta u_{2}^{\prime} & V_{s s}
\end{array}\right| \\
& =\frac{\delta u_{2}^{\prime}}{\Delta} V_{x_{1} x_{1}} \cdot V_{x_{2} s}+\frac{d x_{2}}{d Y_{2}} \cdot s<0 \\
\frac{d s}{d R} & =\frac{1}{\Delta}\left|\begin{array}{ccc}
V_{x_{1} x_{1}} & 0 & 0 \\
0 & V_{x_{2} x_{2}} & -\pi_{2}^{\prime} \cdot u_{2}^{\prime \prime} . s \\
V_{s x_{1}} & \delta V_{s x_{2}} & -\delta R u_{2}^{\prime \prime} \cdot s-\delta u_{2}^{\prime}
\end{array}\right| \\
& =\frac{-\delta u_{2}^{\prime}}{\Delta} V_{x_{1} x_{1}} \cdot V_{x_{2} x_{2}}+\frac{d s}{d Y_{2}} \cdot s
\end{aligned}
$$

The sign of $\frac{d s}{d R}$ is ambiguous because we have a negative income effect associated with an another effect which is positive.

Nevertheless, if we turn to the partial risk aversion coefficient, we find that $s$ increases when $R$ rises. Indeed, the last expression can be rewritten as follows:

$$
\frac{d s}{d R}=\frac{1}{\Delta}\left\{V_{x_{1} x_{1}}+\delta \pi^{\prime \prime}\left(x_{2}\right) u^{\prime}\left(c_{2}\right)\left[-u^{\prime}\left(c_{2}\right)-R u^{\prime \prime}\left(c_{2}\right) s\right]\right\}
$$

The term $\left[-u^{\prime}\left(c_{2}\right)-R u^{\prime \prime}\left(c_{2}\right) s\right]$ is ambiguous and can be rewritten as follows:

$$
\delta u^{\prime}\left(c_{2}\right)\left[-1+\left(-\frac{u^{\prime \prime}\left(c_{2}\right)}{u^{\prime}\left(c_{2}\right)} R s\right)\right]
$$

This last expression allows us to observe a partial risk aversion coefficient: $-\frac{u^{\prime \prime}\left(c_{2}\right)}{u^{\prime}\left(c_{2}\right)} R s$. If this coefficient is less than 1 , then $\frac{d s}{d R}>0$. The positive effect is stronger than the income effect.

6/ A change in expected growth: $E(\theta)$

$$
\frac{d x_{1}}{d E(\theta)}=\frac{1}{\Delta}\left|\begin{array}{ccc}
\delta m g^{\prime}\left(k_{1}\right) & 0 & V_{x_{1} s} \\
0 & V_{x_{2} x_{2}} & V_{x_{2} s} \\
0 & \delta V_{s x_{2}} & V_{s s}
\end{array}\right|<0
$$




$$
\begin{aligned}
& \frac{d x_{2}}{d E(\theta)}=\frac{1}{\Delta}\left|\begin{array}{ccc}
V_{x_{1} x_{1}} & \delta m g^{\prime}\left(k_{1}\right) & V_{x_{1} s} \\
0 & 0 & V_{x_{2} s} \\
V_{s x_{1}} & 0 & V_{s s}
\end{array}\right|>0 \\
& \frac{d s}{d E(\theta)}=\frac{1}{\Delta}\left|\begin{array}{ccc}
V_{x_{1} x_{1}} & 0 & \delta m g^{\prime}\left(k_{1}\right) \\
0 & V_{x_{2} x_{2}} & 0 \\
V_{s x_{1}} & \delta V_{s x_{2}} & 0
\end{array}\right|<0
\end{aligned}
$$

